BULLETIN Bulletin hispanique

HISPANIQUE Université Michel de Montaigne Bordeaux

110-1 | 2008

Varia

\title{
Le traité des armes de Diego de Valera, vers
}

\section{$1455-1460$}

\section{Béatrice Leroy}

\section{(2) OpenEdition}

1 Journals

Édition électronique

URL : https://journals.openedition.org/bulletinhispanique/649

DOI : 10.4000/bulletinhispanique.649

ISSN : $1775-3821$

Éditeur

Presses universitaires de Bordeaux

\section{Édition imprimée}

Date de publication : 1 juin 2008

Pagination : 283-318

ISBN : 978-2-86781-511-9

ISSN : 0007-4640

\section{Référence électronique}

Béatrice Leroy, «Le traité des armes de Diego de Valera, vers 1455-1460 », Bulletin hispanique [En ligne], 110-1 | 2008, document 10, mis en ligne le 01 juin 2011, consulté le 18 septembre 2021. URL: http://journals.openedition.org/bulletinhispanique/649; DOI : https://doi.org/10.4000/

bulletinhispanique.649 


\title{
Le traité des armes de Diego de Valera, vers $1455-1460$
}

\author{
BÉATRICE LEROY \\ Université de Pau et des Pays de l'Adour
}

Diego de Valera, maître d'Armes de la cour de Castille, a offert vers 1455-1460 un Traité des Armes au roi du Portugal. Il y rappelle d'abord la législation en vigueur en Espagne, en France, ailleurs en Europe, concernant les défis et les " emprises d'armes " où s'affrontent les nobles en combats singuliers soutenus devant les cours. Il évoque les cas de trahison qui suscitent ces défis. Puis, il détaille les principes de l'héraldique.

Diego de Valera, Mestre de Armas de Castilla, ofrece hacia 1455-1460 un Tratado de las Armas al rey de Portugal. Recuerda la legislación de España y Francia relativa a los retos y " empresas de armas " sostenidos por los nobles en torneos delante de las cortes reales. Menciona los casos de traición, causa de esos desafios, describiendo además las normas de la heráldica.

Diego de Valera, Fencing-Master in the royal court of Castile, wrote for the king of Portugal, towards 1455-1460, a Treaty of Arms. He examines the laws of Spain, France, Europe on duels and the "Emprises of Arms " where noblemen were engaged in single combats before royal courts. He evokes the various treasons which lead to those duels. Then, he enumerates the rudiments of Heraldry.

Mots-clés : Noblesse - Trahison - Défi - Combat singulier - Héraldique $\mathrm{XV}$ siècle - Diego de Valera.

T $\mathrm{E} \mathrm{XV}^{\mathrm{e}}$ siècle dans les États d'Occident est vibrant d'affrontements militaires; les personnalités qui ont la charge de la vie politique de leur royaume s'affirment difficilement, dans le sang et les larmes le plus souvent,

$B H i$, Tome 110, n $^{\circ} 1$ - juin 2008 - p. 283 à 318. 
la reconquête française après les drames de la guerre franco-anglaise, les guerres hussites et la résistance contre l'avance ottomane en Europe centrale, la guerre dite des Deux Roses en Angleterre, des guerres civiles très pénibles en péninsule ibérique où la Reconquista ne s'arrête elle-même qu'en 1492. Un auteur traverse ce siècle, Diego de Valera, un Castillan (1412-1488), et il nous laisse divers témoignages écrits d'une expérience très engagée et très originale. Son Traité des Armes n'est pas une grande œuvre politique, mais il reflète les préoccupations de la noblesse de ce temps, et il mérite certainement une traduction en français de $2006^{1}$.

Car Diego de Valera a été traduit dès le XVe siècle, par Hugues de Salve, prévôt de Furnes dans le comté de Flandre pour le duc de Bourgogne, et son Traité de Noblesse (Espejo de Verdadera Nobleza) imprimé dès 1497. Ce texte était possédé par le Grand Bâtard Antoine, l'un des fils du duc Philippe le Bon, un exemplaire enluminé est gardé dans la Bibliothèque Royale de Bruxelles ${ }^{2}$. L'ensemble de ses lettres et de ses traités (dont il convient de citer les plus célèbres, outre ce Miroir de Véritable Noblesse, le Doctrinal des Princes, la Défense des Femmes Vertueuses) a été édité par Mario PENNA dans Prosistas Castellanos del Siglo XV, 1, BAE, tome 116, Madrid, 1959, le Traité des Armes tenant les pages 117 à 139. Cette édition castillane est la base de notre traduction. L'original se trouve à la Bibliothèque Nationale de Madrid, ms. 12672.

La carrière de Diego de Valera explique cette notoriété. Issu de la nouvelle noblesse de Cuenca par sa mère, María de Valera, qui est de l'aristocratie de cette cité de la Manche castillane, Diego est aussi le fils d'un converso, Alfonso Chirino de Guadalajara, médecin, auteur d'un Menor daño de medicina, Une médecine de moindre mal, médecin du roi Henri III de Castille qui meurt très jeune à la fin de 1406, et des premières années du roi Jean II (1406-1454), roi à 22 mois. Diego de Valera, qui grandit dans la noblesse castillane, est jeune page de Jean II, pour lequel il garde toujours beaucoup de sympathie, et participe très jeune à la vie militaire. En 14371438, il est dans le camp d'Albert de Habsbourg, Roi des Romains, gendre de l'empereur Sigismond de Luxembourg, qui est mort en 1437, faisant

1. Ce traité est lui-même dédoublé par l'auteur par un traité très bref, Preheminencias y cargos de los oficiales de armas publié avec ses autres traités et lettres. D’ordinaire, dans ses grands traités, Diego de Valera rédige de nombreuses notes explicatives, montrant son érudition. Il n'en a pas voulu la surcharge dans ce Traité des Armes.

2. "Le Gouvernement des Princes, le Trésor de Noblesse, les fleurs de Valère le Grand ", cf. Martín de Riquer, Heráldica castellana en tiempos de los Reyes Católicos, Barcelone, 1986, p. 24 ; Malcolm Vale, War and Chivalry; warfare and Aristocratic Culture in England, France and Burgundy, at the End of the Middle Ages, Athens, Georgia, 1981, p. 14-31 
la guerre en Bohême, la croisade contre les Hussites. Diego de Valera, un soir sous la tente, est pris à partie par un reître qui avait fait le pèlerinage à Santiago et était passé par le Portugal ; à Batalha, il avait vu l'étendard de Castille, perdu par les troupes de Jean Ier de Trastamare en 1385 à la bataille d'Aljubarrota devant les Portugais de Jean d'Avis ; selon l'Allemand moqueur, le roi de Castille a perdu son enseigne, il aurait perdu le trône! Diego de Valera sait lui répliquer en latin, Albert de Habsbourg assurant la traduction simultanée, en citant Bartole de Sassoferrato, le roi de Castille a peut-être perdu une enseigne, il n'a pas pour autant perdu sa dignité. De retour en Castille, le roi Jean II ravi, a adoubé Diego de Valera (ou plutôt le duc d'Albe au nom du roi, qui n'adoube que les chevaliers de l'Ordre royal de la Banda), et attaché à son service « Mosén » Diego de Valera. L'anecdote a traversé la geste castillane, elle est rapportée dans la Chronique du roi Jean II par Fernán Pérez de Guzmán ${ }^{3}$. Diego de Valera, à 26 ou 27 ans, est donc le Maître d'Armes du roi de Castille, et il va le rester avec son fils Henri IV. Sa réflexion sur les enseignes, la dignité, les armes, la vertu noble, étaye son Miroir de Véritable Noblesse, de 1444, offert à Jean II, et se poursuit dans un Cérémonial des Princes légèrement postérieur, puis encore dans ce Traité des Armes, et dans plusieurs de ses lettres, adressées à des nobles de la cour de Henri IV puis aux Rois Catholiques.

Car Diego de Valera a une longue vie politique, qu'il jalonne d'écrits. Serviteur de Jean II, il sait lui adresser des conseils, quelques reproches voilés ; il s'oppose surtout au Privado du roi, son favori don Álvaro de Luna, qui a pris la place de bien des véritables nobles castillans et a cumulé titres, distinctions, fortune, qui mène la politique du royaume et provoque contre lui l'affrontement armé de la noblesse. Valera, attaché aux seigneurs de Zúñiga puis aux Mendoza, contribue en 1453 à faire arrêter Álvaro de Luna, qui est décapité à Valladolid. Mais Jean II meurt en 1454, son fils Henri IV lui succède (1454-1474). Pour Diego de Valera, ce roi n’a aucune des qualités attendues. Il est également mené par des Privados, et Valera adresse à l'un d'eux, le plus influent, le plus intelligent peut-être, mais le plus contestable, Juan Pacheco de Villena, son Cirimonial de los Principes; ce roi ne sait pas remporter les victoires voulues sur les Maures de Grenade, il nomme de mauvais gestionnaires dans le gouvernement. Diego de Valera, pour lequel l'Histoire est naturellement un Exemple, écrit l'une des Chroniques du roi Henri IV, Memorial de Diversas Hazañas, Mémorial de Quelques Hauts

3. Bartole de Sassoferrato, 1313-1359, a rédigé son traité de insigniis et armis en 1359 à la fin de sa vie. Diego de Valera lui en est constamment redevable. On peut dire qu'il est également influencé par l'Orden de Caballería de Ramon Lull, et encore par l'Arbre des Batailles d'Honoré Bouvet du XIV siècle. 
Faits ${ }^{4}$, une suite d'attaques acerbes contre le malheureux souverain, qui est détrôné par une partie de la noblesse de Castille et qui fait perdre le renom de sa patrie. Mais Diego de Valera suit une carrière politique, commencée sous Jean II : procureur de Cuenca aux Cortes, puis Corregidor de Cuenca et de Ségovie sous Henri IV. Il l'est toujours à l'avènement des Rois Catholiques, qu'il salue avec allégresse, pour lesquels il rédige une Chronique et auxquels il adresse des lettres élogieuses, auxquelles les rois répondent et dont ils tiennent grand compte. Car Diego de Valera, avec son fils Charles, qui aura la charge de l'Amirauté de Guinée, a la responsabilité de la flotte du Détroit et il participe par les armes autant que par ses conseils écrits, aux premiers évènements de la Guerre de Grenade 5 .

Cette personnalité si complexe est, pour ce qui intéresse ce propos, très représentative des interrogations de la noblesse du milieu du XV siècle, de sa volonté de mise en scène et de représentation dans de grands moments de la vie de cour. Étant maître d'Armes, il est naturellement passionné par les tournois et les pas d'armes, qui sont réservés à la noblesse et qui se déroulent alors dans l'ensemble de l'Occident, et qui donnent naissance à de célèbres textes, le Traité de la forme et devis d'un tournoi du roi René d'Anjou-Provence en 1444, étant le plus représentatif ${ }^{6}$. La cour de Bourgogne semble alors donner le ton en la matière ; en 1441, Pierre de Bauffrémont, chambellan du duc Philippe le Bon, a envoyé son héraut Châteaubelin, faire une tournée européenne pour inviter tous les volontaires à participer à son pas d'armes, l'Arbre de Charlemagne, qui se déroule en 1443 à Marsenay; Diego de Valera y représente la Castille et ne tarit plus d'éloges pour la Bourgogne, et il évoque le pas d'armes dans ce texte à propos des devises. L'année précédente, en 1442, il a fait de même à Greenwish, "à trois lieues de Londres " dit-il dans le Cérémonial, au pas d'armes du duc de Gloucester, accompagné de deux hérauts, Toledo et Asturias. Il convient de mentionner le pas d'armes de la Fontaine aux Pleurs, près de Châlons-sur-Saône, animé par Jacques de Lalaing en 1449-1450, ce chevalier du Hainaut que cite Valera, et dont la biographie est connue grâce à Jean Lefèvre de Saint-Rémy, héraut Toison d'Or des ducs de Bourgogne ; l'Emprise de la Joyeuse Garde et l'Emprise du

4. Édition de Juan de Mata Carriazo, Madrid, Espasa-Calpe, 1941. Jean-Pierre Barraque et Béatrice Leroy, Des Ecrits pour les Rois; la pensée politique d'Isidore de Séville aux Rois Catholiques, Presses Universitaires de Limoges, 1999, édition du Doctrinal des Princes de Diego de Valera, p.147-180.

5. B. Leroy, Le Triomphe de l'Espagne Catholique à la fin du Moyen Age ; écrits et témoignages, Presses Universitaires de Limoges, 2004.

6. Noël Coulet, Alice Planche, Françoise Robin, Le roi René, le prince, le mécène, l'écrivain, le mythe, Aix-en-Provence, 1982 
Dragon, données en 1446 par le roi René, le Pas de la Bergère en 1449 par le roi René encore ; ou bien en Castille, à Benavente sur le pont de l'Órbigo, le Pas d'Armes de Suero de Quiñones, de 1434, dont on a le récit dressé par Pero Rodríguez de Lena.

Diego de Valera met en valeur le rôle du roi d'armes, celui des hérauts d'armes, et passe en détail toutes les obligations qui leur incombent un jour de tournoi. Aimant l'histoire ancienne et l'histoire carolingienne, bon lecteur de Valère Maxime et des histoires germaniques, il en réfère avec plaisir, citant la mythologie, Jules César, et Charlemagne. Mais ce Traité des Armes a un sous-titre, et cela forme l'essentiel de ce texte, "des Provocations et des Défis "; il s'agit du duel judiciaire ou du gage de bataille, plus que d'un tournoi en courtoisie entre seigneurs, qui est cependant développé à sa place à la suite. Interdit en France par saint Louis après sa condamnation par l'Eglise, le gage de bataille est cependant autorisé en cas de crime de sang par Philippe le Bel en 1306, et par Alphonse XI de Castille en 1338 dans l'un des Ordenamientos, à Alcalá de Henares, et Diego de Valera en recopie fidèlement les textes, mais appelle Philippe le Bel Philippe III. Le duel judiciaire est l'objet de l'une des lois des Siete Partidas du roi Alphonse $\mathrm{X}$ de Castille, la VII Partie traitant des Accusations et Offenses, et son titre IV, « des Combats », développe six lois le concernant, cette VII Partie étant l'une des sources de Diego de Valera, qui l'interprète à volonté ${ }^{7}$ et s'en sert avec bonheur. En 1441, Pero Carrillo de Huete, le Grand Fauconnier de Jean II, cite dans sa Chronique le texte d'un Riepto, une provocation en duel judiciaire, en termes particulièrement violents, il va sans dire, adressé par un Mendoza à un Ayala ${ }^{8}$. Ce combat à merci, réservé à la noblesse lorsqu'il suit les normes officielles, est donc fort suivi en Castille du XVe siècle et Diego de Valera en fixe toutes les règles, insistant sur la très grande responsabilité des rois d'armes et des juges-diseurs, comme du connétable ou du souverain luimême, puisqu'il s'agit d'un combat à outrance, comme l'auteur le souligne, entrepris pour une raison très grave.

7. Claude Gauvard, Duel Judiciaire, dans le Dictionnaire du Moyen Age, PUF, 2002, p.453; Le Règlement des Conflits au Moyen Age, XXXI ${ }^{e}$ congrès de la SHMESP (Angers 2000), Paris, 2001 ; Robert I. Burns, Las Siete Partidas, trad. anglaise de Samuel Parsons Scott, Philadelphie, 2000, en particulier le tome V, p. 1303 et sq. pour la VII Partida, p. 1328 à 1330 son titre IV, les Combats.

8. Crónica del Halconero de Juan II, Pedro Carrillo de Huete, ed. Juan de Mata Carriazo, Madrid, 1946, chapitre 295, p. 382-384, (il est question d'une trahison à laver dans le sang) : Carta de riepto que fué enviada a Pedro de Ayala fijo de Pero López de Ayala, por parte de Lope de Mendoça. A ti, Pedro de Ayala, cavallero fijo de mal padre, yo Lope de Mendoça...en liogar de paz e saludes, te rrequiero a las armas, con ánimo de convatir e te dar la muerte, si niegas lo que yo afirmo... 
Ce texte est offert à Alphonse V l'Africain, roi de Portugal (14381481), alors que Diego de Valera s'oppose à Henri IV de Castille et montre beaucoup d'admiration pour le souverain portugais. Roi à l'âge de 6 ans à la mort de son père Duarte $I^{\circ}(+1438)$, qui fut un homme de lettres autant qu'un souverain (auteur en 1432 du Leal Conselheiro, le Conseiller fidèle, dans la veine des traités politiques de ce temps des "Gouvernements des Princes »), sous le gouvernement de son tuteur Pedro duc de Coímbra, le roi doit affronter de constants soulèvements de la noblesse ; en 1449, Pedro de Coímbra est tué dans la bataille d'Alfarrobeira par les révoltés menés par d'autres princes ${ }^{9}$. Mais c'est un intellectuel aimant les textes politiques et le droit, auteur de très sages Ordonnances, et le roi bénéficie des réussites des navigateurs portugais découvrant et exploitant les côtes de Guinée et l'ensemble des côtes atlantiques de l'Afrique. Plus tard, contre les Rois Catholiques, Alphonse V de Portugal tente de revendiquer la couronne de Castille et d'envahir cet Etat. Au milieu du XV siècle, l'adresse de Diego de Valera insiste comme il se doit, sur les qualités du " jeune " souverain ; selon les âges de la vie, évoqués, le roi Alphonse $\mathrm{V}$ a une vingtaine d'années. L'auteur le nomme seigneur d'Alcacer Seguer, dans l'actuel Maroc, qui entre officiellement en 1454 dans la titulature portugaise. Puis, il parle de Jean II de Castille au passé, donc après 1454, de même qu'il évoque les ducs de Bretagne Jean V et François Ier morts respectivement en 1442 et 1450, l'empereur Sigismond en 1437 ; le roi Alphonse V d'Aragon qui meurt en 1458, est évoqué au présent. Le duc Philippe le Bon de Bourgogne, qui meurt en 1467, est bien vivant lorsqu'en parle Diego de Valera. Le traité se situe bien entre 1454 et 1467 , peut-être exactement en 1457-1458, la dernière année du roi Alphonse d'Aragon.

Le texte de Diego de Valera demande une traduction la plus fidèle et la plus rigoureuse possible. Mais il parle en technicien des duels judiciaires, des tournois, et de l'héraldique. Il convient donc d'adapter les termes français traditionnellement consacrés à ces sujets, au vocabulaire de Diego de Valera. Les " armes nécessaires » sont les armes à outrance, et les "volontaires ", de courtoisie. Il faut faire affronter le provocateur et le provoqué, ou l'appelant et le défendant, pour ces emprises d'armes ou ces combats ; les juges-diseurs sont les arbitres du champ clos. Le verbe blasonner peut toujours s'employer pour décrire un blason, qui compte des métaux, l'or et l'argent, et des émaux pour les couleurs fondamentales, que détaille Valera. La règle est de fixer un signe sur un champ, jamais deux émaux ou deux métaux l'un sur l'autre,

9. Humberto Baquero Moreno, La noblesse portugaise pendant le règne d'Alphonse V, Arquivos do Centro Cultural Português, vol. XXVI, Lisbonne-Paris, 1989, p. 399-415. 
sinon le blason est faux ou "à enquerre ». Le blason se partage de divers signes, des figures ou des meubles, selon les pièces. Celles-ci sont le chef, la pointe, le pal, la fasce, la bande ; les meubles, le chevron, le giron, l'orle, la croix, le sautoir ; les figures naturelles ( les choses vivantes " selon Diego de Valera) sont les astres, les animaux, les végétaux, et on y ajoute les châteaux ou autres constructions. L'écu peut encore porter des fourrures, telle l'hermine, et des besants, et avoir son champ entier losangé ou échiqueté. Ces pièces, meubles, figures, doivent respecter des proportions, le tiers du champ. Seule la barre, qui tranche l'écu, le "brise ", plus mince que la bande, dénonce un cas de bâtardise. Diego de Valera avait ainsi blasonné à la fin de son Miroir de Véritable Noblesse, et a reproduit ici, sans se recopier textuellement toutefois, ces paragraphes consacrés à l'héraldique. A la fin de chacun des deux traités, les manuscrits portent des dessins à la plume, de l'auteur fort probablement, des partitions les plus courantes du blason, telles le chef, la pointe, ou l'écu échiqueté, ou le mantelet, pour mieux se faire comprendre. Ce Traité des Armes présente également des dessins des cottes d'armes et des enseignes.

Traité écrit par un noble engagé dans l'histoire de son temps, offert à un roi mais adressé tout autant aux nobles de son entourage, voici ce texte de Diego de Valera.

Traité des Armes. Traité des provocations et des défis habituels entre chevaliers et nobles, selon les coutumes d'Espagne, de France et d'Angleterre, dans lequel se trouvent les genres et les sortes de cas de trahison et de mauvais actes perpétrés dans les rencontres d'armes.

Introduction, au très haut et très excellent et très vertueux prince Alphonse, cinquième roi de ce nom de Portugal et d'Algarve, seigneur de Ceuta et d'Alcacer Seguer, pour le traité des armes composé par Mosén Diego de Valera.

Si, prince très excellent, nous devons croire la phrase de Sénèque, qui dit que la terre sera gratifiée lorsque ses princes seront sages, votre terre peut s'en targuer, car l'illustre renommée à votre sujet le proclame dans tout le monde. Depuis votre petite enfance, votre enfance, votre adolescence, et pas moins maintenant dans votre jeunesse, votre très illustre et haute intelligence sest exercée en diverses sciences. Vous n'en avez pas pour autant délaissé votre office royal, mais avec prudence, vous traitez chaque chose en son temps selon ce qui est requis par l'occasion et l'objet. Plus loin encore que tout conseil, sachez ce que dit Salomon, et sachez combien Scipion ou encore Hannibal ont voulu d'efficacité, d'effort, et d'audace virile; là ò̀ on recherche la libéralité, il faut revenir à Trajan et à 


\section{BULLETIN HISPANIQUE}

Alexandre. Celui qui désire un exemple de vertu, ne peut le trouver en-dehors de vous, et véritablement on peut dire de vous ce que la discrète reine de Saba disait au roi Salomon: "Bienheureux sont tes serviteurs qui continuellement t'observent toi-même puis tes auvres". Celles-ci, Prince très illustre, me poussent à me mettre à votre service avec une ardente volonté et un profond désir; comme très souvent, j'ai mesuré la grandeur d'un si haut prince et la bassesse de mon état et de mes possibilités, j'ai pensé, puisque je ne pouvais autrement vous servir, composer pour vous cette présente cuvre. Celle-ci, telle qu'elle est, après tant de hautes études et de riches sciences que vous possédez, sera pour vous une sorte de délassement et de récréation après le travail, et je supplie humblement Votre Altesse de bien vouloir la lire, non pas pour son mérite, ni pour l'autorité de son simple auteur, mais parce qu'elle peut convenir aux chevaliers, plus particulièrement à ceux qui veulent entreprendre des faits d'armes. Prince très humain, je soumets sa correction à Votre Royale Majesté, ainsi qu'aux nobles chevaliers et gentilshommes de votre magnifique maison et cour, qui ont vu et lu plus que je ne l'ai fait; et aux rois d'armes et aux hérauts auxquels revient par leur office l'interprétation de tout ceci, sa correction et son amendement, comme cela leur semblera bon.

Aussi, Prince très victorieux, le présent traité sera partagé en trois parties principales. La première traitera des armes à outrance (armas necesarias), dans les cas de duels judiciaires, en décrivant le droit, les coutumes et les cérémonies qui se suivent dans ces faits d'armes en France, Espagne et Angleterre, pour le provocateur et le provoqué, et pour le prince et le juge. La seconde traitera des armes de courtoisie (armas voluntarias), que sans nécessité quelques uns provoquent, en fixant la forme qui est établie de façon la plus éprouvée à leur sujet dans la majeure partie du monde. La troisieme portera sur les enseignes que les rois, les princes, les chevaliers et les gentilshommes portent, quelles armes nous nommons habituellement, en exposant leurs principes et leurs fondements, le droit et le blason, en montrant combien on compte d'enseignes et de cottes d'armes, et par quelles dignités ou personnes chacune d'entre elles peut être portée.

\section{Le Droit des armes nécessaires selon la coutume de France}

Commençons donc ce que nous avons promis. Prince très catholique, le droit des armes à outrance, duels judiciaires ou gages de bataille, fut tel, en France dans les anciens temps, selon le Quatrième Livre de l'Histoire Teutonique, qui parle des anciennes lois de France, que pour quelque injure, quelque mal ou tort causé par un noble (hidalgo) à un autre sans l'avoir prévenu au préalable, ou encore causé à un père, une mère, une sour, ou à une cousine, ou à une parente 


\section{LE TRAITÉ DES ARMES DE DIEGO DE VALERA, VERS I455-I460}

se trouvant en-dehors du territoire, ou à un Ordre, ou à quelqu'un d'un âge ne lui permettant pas le combat, il fallait tout de suite proclamer le défi, le duel ou le gage de bataille, sauf s'il s'agissait d'un vol. Par la suite, vus les grands maux, les inimitiés, les destructions qui s'ensuivaient de tels appels vis-à-vis des nobles, le roi Philippe, troisième de ce nom en France, ordonna avec le conseil et l'accord des trois Etats, qu'on ne donnât plus licence à de telles saisies ou tels gages de batailles, en aucun cas. Il ordonna que les hidalgos comme les autres, en appellent de leurs injures et de leurs torts devant ses juges. Mais à cause de cela, beaucoup de mauvaises gens cherchèrent à commettre dans le secret homicides et autres énormes délits et mauvais actes, car ils savaient bien qu'ils nauraient $p u$ avancer de garantie suffisante ni figurer en bataille. Aussi, le dit roi Philippe voulant trancher, émit la suivante loi ou ordonnance, qui s'observe toujours aujourd'hui dans toute la seigneurie du roi de France.

Loi. Philippe, par la grâce de Dieu roi de France, à tous ceux qui les présentes lettres verront, Salut. Nous vous faisons savoir que, dans le temps passé, dans nos guerres et autres justes causes, pour le bien et le profit commun de nos royaumes, Nous avons de façon générale défendu tout gage de bataille entre nos sujets; mais beaucoup de malfaiteurs ont eu l'audace et osent commettre des homicides et autres graves délits et mauvaises actions secrètement, car ils ne peuvent avoir de témoins et pensent ainsi ne pas être condamnés, ni être traduits en bataille selon la dite ordonnance. Aussi, maintenant, Nous, désirant trancher à ce sujet et ne voulant plus donner occasion à ces mauvaises gens de mal agir, nous avons décidé ceci sur ce point. Lorsque sera évident qu'un homicide ou quelque autre maléfice sera commis dans un esprit de trahison, avec des pièges, sur mauvais conseil ou fausse parole, et qu'une peine de mort doit s'ensuivre, si celui qui a commis cette faute ne peut avancer de témoins suffisants ou alors des gens trop douteux, nous voulons que, par défaut de toute preuve, celui-là ou ceux-là pourront tout de même être traduits en bataille, si par indices ou présomptions proches de la vérité ils sont suspectés de tels faits et diffamés, et nous voulons accepter, dans ce seul cas particulier, les gages de bataille. Dans ces cas, nous adapterons notre défense susdite, dans les lieux et espaces dans lesquels les gages de bataille se livraient, avant notre nouvelle défense. Ce n'est pas notre intention en ce point, que cette défense soit reportée et adaptée aux cas anciens survenus avant la date de ces lettres, pour lesquels la condamnation ou l'absolution a déjà été prononcée, et sur lesquels l'enquête a déjà été menée, pour qu'on prononce à nouveau un jugement 


\title{
BULLETIN HISPANIQUE
}

\begin{abstract}
d'absolution ou de condamnation. Ce n'est pas non plus notre volonté que cette défense soit reportée ou adaptée à quelque autre cas, et il faut que cette défense ne concerne que le tort reconnu avec évidence tel qu'il a été défini. En témoignage de quoi, nous avons fait sceller les présentes de notre sceau. Donné à Paris, le mercredi après la Trinité l'an de grâce de 1306.
\end{abstract}

La forme qui est suivie en France pour le défi, le duel judiciaire ou le gage de bataille, est celle-ci. Le provocateur (reptador) met sa querelle par écrit devant le connétable, relatant le cas présent, mettant le nom de l'offensant et celui de l'offensé, et le jour et le moment et le lieu où la chose s'est produite, en se gardant bien d'écrire des paroles injurieuses, en se limitant à celles que requiert la nécessité; il doit conclure en disant que le provoqué (reptado), pour avoir commis un tel méfait, est un traître. Alors le connétable doit citer le provoqué, qui doit venir devant lui dans les neuf jours, pour répondre de la querelle qui lui est avancée; à sa venue, le connétable fait alors appeler le provocateur, et lui demande sil maintient cette querelle causée contre lui par Untel qui se trouve là, et le provocateur doit répondre que oui. Alors le connétable fait lire la querelle devant tous les deux, et le provoqué répond au provocateur sur tout ce qui est dit, en parlant avec révérence du roi, de sa cour, et de son connétable, lequel demande quil répare les injures qui ont été proférées, d'une réparation aussi honorable que le demande le cas présent. Il dit encore que celui-là a menti et ment comme un faux témoin en tout ce qui a été avancé, et quil se défendra contre lui avec l'aide de Dieu, un endroit pour cela ayant été assigné par le roi, un jour et une heure pour le combattre avec ses armes et à cheval selon la coutume de France. Le connétable demande alors au provocateur si ce qu'il a dit peut être prouvé par des témoins ou de quelque autre façon, et le provocateur répond quil ne peut le prouver; mais que la vérité est telle quill a cherché une querelle et qu'il demande de proclamer que le fait sest déroulé ainsi, et quil supplie le connétable, vicaire général et lieutenant du roi, de trancher en ce cas, de proclamer que le fait sest ainsi passé et qu'il décide contre celui-là les grandes peines prévues dans les lois de France. Si celui-ci veut nier tout cela, il le combattra personnellement, en champ clos selon la coutume de France, et il lui fera confesser de sa bouche même que tout s'est déroulé comme il l'a dit, ou bien il le tuera sur ce champ, ou il l'expulsera au-dehors, ou lui-même mourra en défendant la vérité quil proclame. Le provoqué dit alors quil ment en tout ce quil dit, et qu'il est prêt à se défendre contre lui avec l'aide de Dieu ou à mourir sur le champ clos en défendant sa vérité et sa justice.

Ce procès doit être couché par écrit par le connétable, et lui-même doit établir que cela donne lieu à une bataille, et que cette bataille est juste, en disant: 
"Vue la requête présentée devant moi par Untel, chevalier ou gentilhomme provocateur, et Untel, provoqué, jétablis, que selon les lois de France, le dit Untel, provocateur, a toute justice pour défier le dit Untel provoqué, et le dit Untel provoqué a toute justice pour se défendre. Aussi, moi, connétable de France et vicaire général et lieutenant du roi mon seigneur, je déclare juste la bataille emprise entre les dits Untel et Untel, remettant au roi mon seigneur la liberté, en tant que souverain, de leur assigner place, jour, et heure pour la dite bataille".

Cette sentence étant donnée par le connétable, les dits provocateur et provoqué donnent des garants qui seront présents, aux termes assignés par le roi, et qui accompliront tout ce qui leur sera ordonné par le seigneur roi et par son connétable; alors le connétable fait établir une trêve entre le provocateur et le provoqué et entre leurs parents et amis, jusqu'au jour de la bataille, lesquelles trêves il ordonne que le provocateur et le provoqué et leurs parents et amis observent absolument.

Le roi sachant cette conclusion, assigne une place, une borne, un jour et une heure, et des armes avec lesquelles ils doivent combattre. Le temps fixé doit être de quarante jours, pendant lequel ils peuvent s'accorder sills le désirent, ou alors se rendre à la bataille en présence du roi. L'heure assignée pour le provocateur est une heure avant midi, et pour le provoqué midi exactement. Les armes sont les lances, les épées, les dagues, égales pour l'un et l'autre, et les harnais habituels aux combats.

Le roi fait dresser les lices de 80 pas de longueur et 70 de largeur, et de hauteur habituelle de une coudée. Sur un côté des lices, on dresse un grand échafaudage de trois niveaux; sur le premier, le plus bas, se tiennent les officiers d'armes, sur le second le connétable et les maréchaux, et sur le troisième le roi, avec les ducs, comtes, barons et chevaliers. La lice doit avoir deux portes, l'une à l'orient et l'autre à l'occident, et avant que les deux combattants n'entrent en lice, un sergent ou héraut proclame à haute voix : "Oyez, oyez, oyez! le connétable vous mande et défend, au nom du roi notre seigneur, que quiconque n'ait l'audace de porter des armes offensives ou défensives, sous peine de la vie et des biens, à part ceux qui sont placés par le dit seigneur roi et par son connétable pour garder le camp en sécurité; on vous mande et défend que personne n'ait l'audace de s'approcher des lices à moins de vingt pas, sous la dite peine; de plus, que personne n'ait l'audace de venir à cheval, sous peine de le perdre, à part les deux combattants et ceux qui ont l'ordre de venir ainsi montés; ceux-ci, arrivant aux lices, seront obligés de remettre ces chevaux, à moins de les perdre. "De même encore le connétable ordonne que tous s'asseyent par terre, sous peine de la grâce $d u$ roi, pour que tous puissent voir la bataille.

Le provocateur entre par la porte de l'orient, armé du harnais complet, la visière baissée, la lance dans la main, dans l'équipage dans lequel il combattra, 


\section{BULLETIN HISPANIQUE}

et le connétable et les maréchaux se tiennent alors à cette porte. Le connétable demande alors qui est cet homme qui s'avance; et il doit répondre : "Je suis Untel, chevalier ou gentilhomme, je viens combattre Untel, mon adversaire ". Et le connétable lui fait lever la visière pour voir son visage, puis il la lui fait baisser et le fait entrer en lice. Ainsi, le provocateur va devant le roi, lui fait la révérence, et un officier d'armes venu avec lui, lit à haute voix devant le roi un écrit:

"Très haut et très excellent et très puissant prince, roi et seigneur. Voyez ici Untel, chevalier ou gentilhomme, qui se présente devant Votre Seigneurie, prêt, comme il se doit, pour combattre Untel, son adversaire, avec l'aide de Dieu et de Notre Dame et du seigneur saint Denis; il est prêt à mener à la vérité les choses qu'il a proférées contre son adversaire et pour lesquelles la bataille est menée en justice, selon la forme et la manière qui ont été ordonnées par votre cour. Il vous supplie d'ordonner la répartition du champ, du soleil et du vent, et de tout ce qui, en tel cas, est convenable et profitable. Il demande de pouvoir changer de cheval et d'armes s'il est nécessaire, de combattre à pied ou à cheval comme on le verra pour le mieux, de monter à cheval ou d'en descendre toutes les fois qu'il sera reconnu être nécessaire, d'allonger ou de raccourcir ses étriers, de baisser ou de lever sa visière de toutes les façons où il le voudra, de s'aider de toutes les armes ou de laisser celles qu'il choisira, et de revenir les prendre toutes les fois qu'il sera nécessaire. Il demande à Votre Altesse de proclamer vaincu son adversaire s'il tire les armes à l'encontre de la coutume de France, ou des armes faites par sorcellerie ou autre mauvais art ou mauvaise façon. Il déclare et demande que si le dit adversaire ne vient pas dans le champ à l'heure fixée par le roi, qu'il soit proclamé vaincu et que dorénavant il ne soit plus reçu, où qu'il aille, et que lui soient données les peines dont disposent les lois de France dans ce cas-là. Il déclare de même que, si par hasard il ne peut vaincre son adversaire ce jour-ci, qu'il ait le jour suivant pour le combattre à nouveau, et qu'il puisse disposer de tout ce qui est convenable, nécessaire et idoine en ce cas. Tout cela, il supplie et demande que Votre Altesse le lui accorde selon l'usage et la coutume de France."

Le provoqué entre par la porte occidentale et proclame un autre engagement semblable au précédent et prononce de semblables protestations, lesquelles, venues du provocateur et du provoqué, sont données par écrit au connétable.

Les chevaliers entrés, le provocateur placé du côté droit du roi et le provoqué du côté gauche, un roi d'armes, ayant revêtu la cotte d'armes royale, crie à haute voix à quatre reprises, aux quatre coins des lices depuis l'intérieur : "Oyez, Oyez, Oyez, le très puissant, très craint et très excellent prince le roi notre seigneur, vous mande et défend que personne n'ait l'audace de parler ni de faire des signes pouvant aider l'un des combattants, lui porter assistance de quelque façon, sous peine de la vie et des biens. "Alors demeurent seuls les deux combattants à 


\section{LE TRAITÉ DES ARMES DE DIEGO DE VALERA, VERS I455-I 460}

l'intérieur des lices, et avec eux, deux autres chevaliers commis par le roi pour les conseiller, et puis encore quatre autres chevaliers gentilshommes à pied, armés de tout leur harnais, tenant des bâtons à la main pour les séparer si le roi le demande. Alors le connétable et les maréchaux leur attribuent le champ, le soleil et le vent et en sa présence, avant le combat, le provocateur et le provoqué prononcent trois serments sur un missel, selon la forme suivante :

Le connétable appelle le provocateur et lui dit: "Vous, Untel, jurez-vous sur les Saints Evangiles que vous touchez de votre main droite, par la foi et le baptême reçus de Dieu, que vous croyez que c'est pour une bonne et juste cause que vous attaquez Untel votre adversaire, et que vous pensez et croyez qu'il n'a qu'une raison injuste pour se défendre contre vous?" Il doit répondre "Oui, je le jure"; et un serment semblable est reçu par le connétable du provoqué.

Alors, le connétable fait poser la main droite au provocateur sur le missel et dit: "Jurez-vous sur les Saints Evangiles que vous touchez de votre main droite, dans la foi et le baptême reçus de Dieu, que vous ne portez sur vous ni sur votre cheval ni d'une autre façon, quelques pierres, ni des mots ou des phrases de sorcellerie ou de charme, ni d'armes façonnées par des magiciens, ou frauduleuses, que vous ne portez que ce qui vous a été assigné par le roi mon seigneur ou par moi, que vous n'avez pas autre chose vous donnant l'assurance de la victoire, sauf en Dieu et en votre juste querelle, en votre personne, en vos armes loyales et en votre cheval?" Et il répond "Oui, je le jure ». Et le même serment est reçu du provoqué. Alors le connétable fait venir ensemble les deux combattants, provocateur et provoqué, et il les fait se tenir par les mains gauches, leur main droite posée sur le missel, et le provocateur dit le premier: "Toi, homme que je tiens par la main, je jure sur ces Saints Evangiles, par la foi et le baptême que j'ai reçus de Dieu, que la cause pour laquelle je t'ai conduit en bataille, je la crois véritable et juste pour te combattre, et je pense que tu as une cause mauvaise et injuste pour te défendre ainsi. "Et le provoqué répond: "Je jure sur les Saints Evangiles, par la foi et le baptême reçus de Dieu, que tu as une cause mensongère et mauvaise pour mappeler en bataille, et j'ai moi-même une cause bonne, loyale et véritable pour me défendre contre toi. "Ces serments prononcés, chacun d'eux baise un crucifix que tient un prêtre, puis chacun s'en va de son côté, accompagné du chevalier posté pour le conseiller. Ainsi se présentent-ils l'un contre l'autre.

Ici, il faut que le connétable observe avec grande diligence si le roi ordonne de les séparer pour se reposer, ou dans le cas où la bataille n'aurait pas de conclusion en un seul jour, et en ce cas chacun d'eux doit observer ce temps de séparation; il faut voir les armes, et voir si l'un d'eux a un avantage sur l'autre à propos $d u$ soleil et $d u$ vent, ou quelque autre avantage. En ce cas, le connétable doit les ramener dans la bataille, sauf si le roi décide de les retirer du champ pour bonne fin. Il doit de même écouter toutes les paroles prononcées par chacun des 


\section{BULLETIN HISPANIQUE}

deux combattants, car en ce cas, après le roi, c'est le connétable seul qui décide et personne d'autre.

Alors, tous deux vont l'un contre l'autre pour combattre et faire leur devoir. S'il arrive que, forcé par l'autre, l'un d'eux est réduit à une telle extrémité qu'il doit confesser de sa propre bouche qu'il suit une querelle injuste ou défend une cause injuste, et qu'il se rend à la volonté de l'autre, celui-là est soumis à la justice du roi et emmené au marché et là, le bourreau lui coupe la tête, et son corps est exposé sans sépulture durant trois jours, et ses fils nés après l'événement qui est cause de la condamnation, sont proclamés traîtres, et dorénavant ne peuvent ni porter foi ni défier ni prêter plaid et hommage, eux, leurs fils et leurs petits-fils. Ils ne peuvent assumer d'office public ni autre honneur réservé aux nobles. S'il arrive que l'un d'eux meure dans les lices sans être reconnu coupable de tout ceci, il demeure valeureux, lui et tout son lignage, autant que celui qui l'a tué. Les biens de celui contre qui se déroule la justice, sont confisqués à la chambre du roi, une fois payées les dépenses du vainqueur jusqu'à 100 francs, que les officiers d'armes prélèvent sur les biens du vaincu; et le cheval est donné au connétable, les armes aux maréchaux, les lices et les tribunes restent aux officiers d'armes.

S'il arrive que le roi décide que tous deux sont valeureux, les maréchaux font sortir le premier le provoqué par la porte occidentale, et peu après le connétable fait sortir le provocateur par la porte orientale; les officiers d'armes reçoivent $d u$ roi les 100 francs qu'ils auraient dî prendre sur les biens du vaincu si la bataille avait été menée à son terme; de même, le roi leur fait donner ces 100 francs si l'un d'eux meurt dans son droit sur le champ. Ceux qui sont déclarés valeureux par le roi, il est habituel de leur donner des privilèges et de les adouber chevaliers sils ne le sont pas, le connétable les appelle ses amis et ils mangent avec lui ce jour-là.

\section{Le droit des armes à outrance selon la coutume et le Fuero d'Espagne}

Pour les armes à outrance, selon la coutume et le Fuero d'Espagne, il faut savoir ceci. A la volonté de l'offensé, on peut les choisir entre deux sortes, pour un défi ou une bataille judiciaire. Si c'est au sujet d'un défi, depuis les temps anciens, tout noble qui reçoit un tort, un mal, une atteinte, d'un autre noble, peut pour cela le défier, comme on le lit dans la loi de la VII Partida, au titre 11, écrite par le roi Alphonse X, qui parle des défis.

Loi. Un noble coupable vis-à-vis d'un autre d'un déshonneur, tort ou mal, peut être défié de la façon suivante; on dit: "Je vous reprends l'amitié et je vous défie, pour tel déshonneur, tort ou mal que vous mavez causé, à moi ou à Untel mon parent, 


\section{LE TRAITÉ DES ARMES DE DIEGO DE VALERA, VERS I455-I460}

car j'ai le droit de le faire amender ". De même un homme peut en défier un autre pour le déshonneur ou le tort reçu par son parent, autant que pour ce qu'il aurait reçu lui-même. Non seulement un homme peut en défier un autre pour lui-même, mais aussi il peut le faire pour tout autre qui est noble et ceci peut saccomplir pour quatre raisons. La première, quand un roi veut en défier un autre, car ce n'est pas chose facile d'aller lui-même en défier un autre; la seconde, si un parent veut en défier un autre et a honte de le faire lui-même, en raison de cette proche parenté ; la troisième, s'il faut défier un homme plus puissant que soi et si cela est dangereux de le faire soi-même ; la quatrième, sil défie un homme de moindre état et s'il dédaigne de le faire lui-même.

Quelque temps après, le roi Alphonse, le onzième de ce nom, en Castille et en León, voyant les grands maux élevés entre les nobles d'Espagne qui se lançaient sans cesse de tels défis, ordonna la loi suivante selon une forme nouvelle, pour y suivre désormais le défi et non d'une autre façon.

Loi. Pour arrêter toutes les luttes et querelles soulevées entre les nobles, et les maux et les vols perpétrés dans la terre à cause de défis sans cesse jetés entre eux librement, en-dehors de tout droit, nous avons ordonné dans la réunion que nous avons convoquée l'année de l'Ere de 1376, sur le conseil de Juan Núñez seigneur de Biscaye notre Grand Majordome et notre Alférez, et des autres notables et nobles qui se sont réunis ici avec nous, qu'on ne puisse jamais plus lancer de défi, sauf de la façon décrite dans cet Ordenamiento. Maintenant, dans les Cortes que nous tenons à Alcalá de Henares, ils nous ont demandé en grâce d'abroger cet Ordenamiento, et nous leur octroyons la possibilité de lancer des défis comme cela leur était traditionnel. Nous, avec l'accord de notre cour et leur conseil, ayant vu que ce qu'ils nous demandaient était moins préjudiciable pour eux, nous l'avons jugé bien, et nous l'accordons. Que tout noble puisse en défier un autre, après une blessure, une prison ou une charge menée contre lui. De même, après la mort du père ou de la mère, ou du grand-père ou de la grand-mère, ou des bisä̈eux, ou d'un fils ou d'une fille, ou de petits-enfants, ou la mort d'un frère ou d'une sœur, d'un cousin ou d'une cousine, on frère ou sour de son père ou de sa mère, de cousin ou de cadet de celui qui défie, pour blessure ou prison des hommes dessus dits, ou de tout autre, sils ont un empêchement pour porter leur défi et poursuivre leur 


\section{BULLETIN HISPANIQUE}

ennemi; ou pour les parents dans les degrés susdits, ou pour la femme de celui qui défie, car ce sont des personnes qui ne peuvent défier ni poursuivre; si les hommes susdits, ou n’importe lequel d'entre eux, ne veulent pas défier ou poursuivre, en dédaignant tout cela, alors qu'ils pourraient le faire, aucun de leur parent ne peut le faire à leur place. De plus, si un noble se déplace dans un lieu habité par un autre noble où celui-ci se trouve, ou sa femme ou sa mère, et si le premier blesse ou arrête un serviteur de ce noble qui y réside, celui qui reçoit ce déshonneur peut le défier. Si quelque noble ou valet venu avec un chevalier ou un noble, commet cela, que celui qui est venu avec lui ne l'accepte plus et le rejette loin de lui. S'il est noble, sill l'accueille tout de même sans le repousser, celui qui a reçu le déshonneur peut défier ce noble qui a reçu le noble coupable de ce délit, et celui qui a été accueilli malgré tout, doit être présenté au Merino $d u$ roi ou au provocateur. Si celui qui a commis ce maléfice est un valet, celui qui le fait vivre doit le déclarer au Merino du roi, sill l'a sous la main, et s'il ne fait pas cela, alors que l'offense a été faite, celui qui a reçu le déshonneur et l'injure peut défier ce responsable. Le Merino du roi arrête le valet et le met à la peine selon le Fuero sans tergiverser. De plus, si un noble se rend dans un lieu où réside un autre noble, ou sa femme ou sa mère, et s'il prend par la force quelque chose, il peut être défié pour cet acte, sauf si celui qui a commis cela est justement le Merino ou un autre officier qui a la charge de la justice et le pouvoir pour l'accomplir. Et encore, si un noble couche avec une femme qui est dans la maison d'un autre noble, si le fait est reconnu, sil l'a enlevée et forcée, on peut le défier pour cet acte. Mais pour le reste, on ne peut pas porter de défis. Quand on défiera ou enverra défier, celui qui veut défier doit faire savoir la raison de sa démarche; depuis le jour où il a porté le défi jusqu'au neuvième jour accompli, il ne peut commettre ni tort ni mal, et celui qui défie ou qui envoie défier ne peut tuer le défié, tant que ces neufjours ne se sont pas passés. S'il veut défier pour autre chose que ce qui a été décrit, ou d'une façon différente, le défi est alors déclaré nul, et celui qui l'a porté doit s'exiler du territoire pour deux ans et pendant ce temps, ses biens doivent rester sous la garde du roi; que le roi n'accorde pas son pardon à cet exilé, et sil veut pardonner, soit de sa volonté soit par supplique de l'autre, que pendant les deux années de son exil hors du royaume, il ne puisse ni en appeler ni entamer une querelle, personne ne pouvant l'écouter, quelle que soit sa plainte ou sa demande. Si un noble en défie un autre pour ce qui vient d'être dit ou pour l'un 


\section{LE TRAITÉ DES ARMES DE DIEGO DE VALERA, VERS I455-I460}

de ces cas, sil fait porter le défi par d'autres personnes, parents ou amis, ceux qui seront ainsi désignés par lui ne peuvent causer aucun tort personnel ni déshonneur au défié, ni le tuer en-dehors de la présence de celui qui a voulu ce défi, car pour eux-mêmes ils ne peuvent rien causer au défié, ni attaque ni homicide. De plus, nous décidons que, pour tout ce qui est advenu entre les nobles depuis l'Ordenamiento de Burgos jusqu'à aujourd'hui, on pourra défier comme il est dit dans ce texte et pas autrement. Pour tout ce qui se présentera à l'avenir, qu'on suive cet Ordenamiento que nous établissons ici.

Il faut souligner que le défi se déroule seulement entre nobles et personne d'autre; ceci, en rappel de la foi et de l'amitié qui les réunissaient autrefois, car défier n'est pas autre chose que de retirer sa foi ou son amitié entre ceux qui proclament cela. Dans le duel judiciaire, on observait encore en Espagne la loi suivante, transcrite dans la VII Partida sous le titre "des duels judiciaires".

Loi. Tout noble peut défier, pour tout tort ou déshonneur entraînant une trabison ou une félonie de la faute d'un autre noble. Il peut le faire de lui-même s'il est vivant, mais à sa mort peut le faire à sa place son père, ou son fils; et s'il n'a pas ces parents proches, peut défier en sa place tout proche parent de ce défunt, et même peut défier le vassal pour le seigneur et le seigneur pour le vassal. Chacun des amis peut répondre pour un ami s'il est défié, comme on le développera plus loin. Mais pour quelqu'un qui est vivant, personne ne peut répondre à sa place, car dans le duel judiciaire, il n'y a pas de prisonnier, sauflorsque quelqu'un veut défier son seigneur ou une femme ou un homme d'Ordre, ou quiconque ne pouvant ni ne devant porter les armes. Nous établissons que dans ces derniers cas, tous les parents peuvent combattre à la place de celui qui est défié même s'il est vivant. Mais nous disons bien qu'aucun traître, ni son fils, ni le félon, ne peut traduire en duel quelqu'un d'autre, ni celui qui est jugé comme fauteur de quoi que ce soit selon la coutume d'Espagne. De plus, celui qui est défié ne peut en défier un autre, avant d'être lavé de ce premier défi, ni celui qui a été débouté en Cour, enfin personne ne peut défier quelqu'un avec lequel il a une trêve, tant que dure cette trêve. Le défi doit se prononcer devant le roi, car personne d'autre que le roi ne peut déclarer le noble traître ou félon, ni le relever de ce défi, seul le roi le peut, car il en a le pouvoir sur tous. 


\section{BULLETIN HISPANIQUE}

Après ce texte, le susdit roi Alphonse XI a émis la loi suivante, qui sobserve maintenant dans les royaumes de Castille et de León.

Loi. Nous établissons et ordonnons que les duels judiciaires suivent la forme suivante. Tout noble peut intenter en justice tout autre noble qui lui aurait porté tort, déshonneur, trahison ou félonie. Celui qui le peut, peut défier lui-même, mais sỉl est mort, le père le peut pour le fils et le fils pour le père, et le frère pour le frère; sill n'a pas ces parents-là, le plus proche parent du défunt peut alors le faire, jusqu'aux fils cadets des cousins. Nous établissons que le vassal peut défier à la place du seigneur, et le seigneur pour le vassal, et chaque parent du défié jusqu'au quatrième degré peut répondre pour son parent; mais pour un homme en vie, personne ne peut répondre à sa place, car dans un duel judiciaire on ne fait pas de prisonnier, sauf lorsque le défié est le seigneur ou la femme ou un homme d'Ordre, ou quelqu'un ne pouvant ni ne devant porter les armes; nous décrétons que dans ces seuls cas, peut répondre l'un des parents dessus dits, même si le provoqué est en vie. Mais nous proclamons qu'aucun traître ni félon, ni son fils né après la trahison, ne peut provoquer un autre en justice, ni quiconque jugé alors pour autre chose. De plus, personne ne peut en défier un autre s'il est déjà défié, avant d'avoir terminé cette affaire, ni celui qui est condamné en Cour; personne ne peut provoquer celui avec lequel il a une trêve tant que dure celle-ci, sauf si durant la trêve se produit quelque chose qui suscite le duel judiciaire. Nous établissons que le défi ne peut se lancer que devant le roi dans sa Cour et non devant un ricombre ou un merino ni tout autre officier du royaume, car personne d'autre que le roi ne peut déclarer qu'il admet le défi pour félonie, ou au contraire en terminer avec cette provocation, car seul le roi a le pouvoir sur tous. Nous établissons que tout noble peut être provoqué sil a tué ou blessé ou pris un autre noble sans avoir été tout d'abord défié par lui; celui qui provoquerait dans ces conditions, serait alors déclaré félon ${ }^{10}$.

10. Le merino est un administrateur provincial, au XIV siècle. Il est là pour transmettre la loi du roi et non prendre la place du souverain. Le ricombre est au plus haut de la noblesse, mais lui non plus ne peut agir en souverain. La loi d'Alphonse XI est instruite en 1338 pour arrêter tous les combats singuliers devenus guerres de clan, affrontant les grands pendant sa minorité. Seul le roi peut trancher dans les cas de crimes de sang. 
Ces choses rappelées, à propos du défi du noble selon le Fuero et les coutumes d'Espagne, il reste à voir les formes de ce duel judiciaire, et quels sont les cas pour lesquels le noble peut être proclamé traître ou félon, et quels sont les cas de mauvais comportement (menos valer) pour lesquels le noble peut être chassé du duel, ou encore des honneurs dus au noble; tout ceci développé, on peut poursuivre ce qui a été promis.

Je réponds tout d'abord que tout hidalgo qui veut en défier un autre, doit d'abord le faire savoir au roi en secret, en disant: "Seigneur, Untel, chevalier ou gentilhomme, m'a infligé tel tort et je veux le provoquer en Cour devant Votre Seigneurie, car jai le droit de le faire; aussi, je supplie Votre Altesse de m'en donner la licence."

Le roi doit lui répondre en lui demandant sil peut poursuivre son affaire. Sil répond que oui, le roi doit l'admonester et le conseiller pour qu'il s'entende avec son adversaire, en lui donnant pour cela un laps de temps convenable. Au terme fixé, si les deux nobles ne sentendent pas, le provocateur doit faire venir devant le roi celui quil veut défier. Tous deux présents, en public, devant au moins 12 chevaliers, il doit dire : "Seigneur, Untel, chevalier ou gentilhomme, qui se trouve ici devant vous, a commis telle trahison ou telle félonie, en détaillant ce qui a été fait, et où et comment, et j'affirme que pour cela il est traître ou félon. " Et sil le veut, il peut le provoquer par des chartes, par enquête ou par témoin, et il doit alors le dire. Sil veut le duel judiciaire, il doit dire quil mettra les mains sur lui et quil lui fera avouer par sa langue même ou bien quil le tuera ou le chassera du champ une fois vaincu. Et le provoqué doit répondre, toutes les fois qu'on l'appellera traître ou félon, que c'est mensonge. Le provocateur doit répéter cela trois fois en Cour devant le roi, publiquement, comme dessus dit; pendant ces trois jours, le provoqué peut choisir laquelle des façons dessus dites lui permettra de se laver de l'accusation, car il lui faut désormais le faire d'une façon ou d'une autre selon le Fuero ou la coutume d'Espagne, et le roi ne peut autoriser la bataille qu'avec l'accord du défié. Si le provoqué dit qu'il s'en remet aux ordres du roi et non à la bataille, le roi doit fixer au provocateur un laps de temps pour qu'il prouve ce quill a déclaré, et cette preuve doit être apportée par une charte authentique ou par des nobles, mais non par enquête ni d'une autre façon. S'il arrive que le provocateur ne peut prouver ce qu'il a lancé, et si la cause de cette provocation n'est qu'une trahison, il doit recevoir la peine qu'aurait reçue le défié si on avait pu tout prouver contre lui; si on arrête là l'affaire en refusant de la mener plus loin, on doit le proclamer devant le roi en Cour, et renier ce qui a été dit. Si le noble se renie ainsi, par la suite il ne pourra plus provoquer personne ni se porter l'égal d'un autre noble en aucune affaire; mais sil refuse de se renier, le roi doit le chasser de sa terre et le proclamer ennemi de celui quil a défié. Ceci doit être de même observé lorsque ce provocateur ne veut rien prouver 


\section{BULLETIN HISPANIQUE}

par témoins ou par charte authentique, ne voulant que la bataille ou l'enquête royale, et si le provoqué ne veut pas que l'affaire se joue par enquête ou par bataille, et le roi doit alors le dispenser du duel.

Si contre le provoqué a été prouvé ce pour quoi il est accusé ou proclamé félon, il doit être exilé de la terre à jamais et perdre la moitié de tous ses biens, qui sont saisis par le roi.

Le noble, selon le Fuero et la coutume d'Espagne, ne doit pas être exécuté pour cause de félonie, sauf si celle-ci est si grave que quiconque l'a commise doit mourir. S'il est défié pour trahison, le vaincu doit mourir et perdre tous ses biens, saisis par le roi. Tant que dure le procès, le provoqué et le provocateur doivent rester en trêve, de même que leurs amis et parents. S'il arrive que le provoqué meure avant l'issue, lui et son lignage sont déclarés libres de toute accusation. Si le provoqué ne se présente pas aux termes fixés, le provocateur peut le défier en absence, en présence du roi et de la forme susdite, comme sil était présent; il doit supplier le roi que devant cette absence et cette rébellion, il le proclame traître et félon, et le roi doit le faire, en réunissant sa Cour, où, devant tous, il proclame alors: "Vous savez tous qu'Untel, chevalier ou gentilhomme, a été convoqué pour venir entendre le défi qu'Untel a lancé devant moi, il a eu le laps de temps prévu par le droit pour venir se défendre sil le désirait, et si grand a été son tort qu'il n'a pas craint le déshonneur pour lui et pour son lignage, il ne s'est pas excusé ni envoyé quelqu'un pour l'excuser de ce grand mal commis selon ce défi. Quoique cela nous pèse beaucoup de prononcer telle sentence à l'encontre de notre sujet, puisque nous tenons cette charge pour accomplir la justice et parce que tous craignent un tel tort et un tel mal, nous le proclamons traître. Nous ordonnons que dorénavant où qu'il se trouve, il soit exécuté comme traître." Et si c'est le cas de félonie, il doit dire: "Nous le proclamons félon, et nous ordonnons qu'il soit à jamais exilé hors de nos royaumes".

Ce jour-là, le roi doit se trouver sur une estrade tendue de noir et se vêtir de noir, et de même en noir doivent être tous les chevaliers et gentilshommes de la Cour, pour montrer leur douleur, car malgré cette antique amitié connue entre les nobles, ce malheureux chevalier ou gentilhomme a mérité une telle sentence de condamnation.

Un noble défiant un homme puissant ou un grand seigneur, et ce puissant ne voulant pas combattre contre lui, doit alors lui donner compensation de son corps, de sa force, de son lignage, de telle façon que le noble s'en contente. Lorsqu'il veut bien combattre, un noble soutient ce combat à la place de ce grand seigneur puissant; si ce dernier est vaincu, ce puissant a tout de même la peine, même si le noble vaincu a été son procureur et non le principal. Il arrive quelquefois que par manque de savoir ou de conseil, quelqu'un défie sans objet de trahison ou de félonie, alors le provoqué, une fois le provocateur convaincu de son erreur, 
doit demander au roi qu'il accomplisse le droit contre celui qui l'a défié, et le roi, sachant que l'affaire n'est ni de trahison ni de félonie, ne doit pas aller plus loin dans le procès et doit mander au provocateur qu'il revienne sur sa parole et le proclamer ennemi du provoqué.

Si le provocateur et le provoqué s'entendent pour la bataille, le roi leur assigne le jour et l'heure, les armes et le champ, et les juges-diseurs (fieles) qui se placent en ligne. Cette démarcation doit être bornée de telle façon que chacun voie d'où sort l'autre, mais pas sans le mandement exprès du roi et des juges, qui doivent rester au milieu du champ et dire sils portent les armes autorisées par le roi, et qui doivent placer l'un et l'autre selon le soleil et le vent. Tant que ces juges se trouvent dans le champ, chacun peut arranger son cheval et ses armes. Une fois les juges sortis, ceux-ci doivent cependant rester tout près pour voir et entendre les combattants. Alors, le provocateur doit commencer la bataille, et si cet appelant ne la commence pas et se détourne, le défendant peut la commencer à sa discrétion. Avant que les combattants n'entament la bataille, le connétable, par ordre du roi, fait proclamer par tout le champ que personne n'ait l'audace de faire des signes ni de parler de façon à renseigner ou aider l'un ou l'autre des combattants, sous peine de mort. Si l'un des combattants sécarte de la ligne de séparation sans l'ordre du roi ou des juges, de sa seule volonté ou par la force de son adversaire, il est proclamé traître ou félon selon l'affaire du défi, sauf s'il s'agit de mauvais pas du cheval ou d'une rêne rompue, ou pour tout autre cause au su et au vu de tous les juges, contre sa volonté et non pas des coups de l'adversaire; alors, il retourne dans le champ à pied ou à cheval, pour le mieux, car en ce cas il n'est pas vaincu. Pour celui qui meurt dans le champ sans être proclamé vaincu ni répondant à la cause du défi, ce défi nétant pas encore lavé, on proclame que lui, tout son lignage, et celui qui l'a tué, restent dans le droit. Mais celui qui est proclamé traître doit être mis à mort et ses biens saisis par le roi. S'il est proclamé félon, il doit être exilé de la terre à jamais, et perdre la moitié de ses biens, remis au roi, sauf si la cause du défi est telle que tout coupable doit être exécuté. Le cheval et les armes du vaincu sont donnés au majordome du roi.

\section{Les cas de trahison}

Selon le Fuero et la coutume d'Espagne, on compte quatorze cas de trahison ${ }^{11}$. Lorsque quelqu'un conspire à la mort du roi ou à la façon de lui faire perdre la dignité royale. Si quelqu'un passe à l'ennemi et fait la guerre à son roi et à son royaume, aide à le faire, ou conseille l'ennemi, lui envoie des lettres et des avis pour l'avertir de certains faits portant tort au roi et à la terre. Si quelqu'un

11. VII ${ }^{e}$ Partida, Titre II, "des Trahisons", Op. cit. p. 1318-1321. La première Loi énonce les cas de Lèse Majesté, que détaille ici Diego de Valera sans employer le terme. 


\section{BULLETIN HISPANIQUE}

cuvre pour pousser à la révolte un territoire et le soulever contre le roi ou refuser l'obéissance, comme c'était habituel jusque là. Si un roi ou un seigneur extérieur au royaume veut donner sa terre ou lui payer des pactes d'alliance, et si quelqu'un du royaume s'y oppose. Si quelqu'un tient un château ou une ville du roi ou d'un seigneur et sil se soulève contre lui et le donne aux ennemis ou le perd par sa faute ou par quelque fourberie, ou encore si un chevalier ou un ricombre bâtit une forteresse contre le roi ou portant malheur au royaume. Si quelqu'un abandonne le roi dans la bataille et passe à l'ennemi ou entre dans un parti sans son ordre, ou dévoile aux ennemis les secrets $d u$ roi, pour son malheur. Si quelqu'un fomente un trouble ou un soulèvement dans le royaume en réunissant des serments et des conjurations de chevaliers ou de villes contre le roi, d'où naît le mal pour le roi ou pour le royaume. Si quelqu'un tue l'un des Adelantados Mayores du royaume ou des hommes honorables du Conseil ou des chevaliers établis à la garde de la personne royale, ou des juges qui ont le pouvoir de juger les procès en cour. Si, lorsque le roi a donné sa sauvegarde à quelqu'un en particulier ou aux gens d'un certain lieu ou à la province, des gens de cette seigneurie rompent cette sauvegarde en tuant ou blessant ou déshonorant ceux qui étaient protégés par ce privilège. Si, lorsque le roi garde des otages, quelqu'un de sa seigneurie les tue ou les blesse. Si, lorsque quelqu'un est pris pour fait de trahison, quelqu'un le fait sauver ou tente de le faire. Si le roi prive quelqu'un de l'office qu'il lui avait confié pour le donner à un autre, si le premier refuse de l'abandonner, ou s'il a une forteresse et ne veut pas la remettre à celui à qui le roi ordonne de la lui confier avec tout ce qui en relève. Si quelqu'un brûle ou détruit avec malignité une représentation du roi faite en son honneur. Enfin, si quelqu'un frappe fausse monnaie ou des sceaux royaux imités.

Lorsqu'on commet l'une de ces quatorze actions contre un autre seigneur ou contre un autre homme, celui qui est coupable est félon selon le Fuero et la coutume d'Espagne. Est de même félon tout noble qui tue, blesse, ou prend ou pourchasse un autre noble sans l'avoir auparavant défié, sauf devant la justice.

\section{Les cas de mauvais comportement}

Il y a essentiellement deux cas de mauvais comportement, selon le Fuero et la coutume d'Espagne. D'abord, lorsqu'un noble prête plaid et hommage d'accomplir telle chose et ne le fait pas ou pas au terme fixé. Deuxièmement, lorsqu'un noble se dédit en jugement ou en cour de ce qu'il avait annoncé. Tombent ainsi dans ces cas de mauvais comportement les nobles qui deviennent bouffons, jongleurs publics, ceux qui font des pantomimes et chantent et dansent pour de l'argent, ou les usuriers, et ceux qui exhibent des bêtes sauvages pour de l'argent; et de 
façon générale, tous ceux qui commettent les cas évoqués dans la IV Loi du titre "Infâmes", dans la VII Partida".

Entre les cérémonies de France et d'Espagne, il n'y a guère de différence, aussi je ne le répète pas ici.

\section{Le droit des armes à outrance selon la loi d'Angleterre}

On a vu comment connaître et manier les armes, selon le Fuero et la coutume d'Espagne; il faut maintenant évoquer ce qui se pratique en Angleterre à ce sujet. Selon les lois et coutumes d'Angleterre, tout noble qui porte injure à un autre, ou du mal ou un tort, sans l'avertir au préalable, et fait de même contre un père, une mère, un frère, une saur, un parent dans le quatrième degré, qui seraient morts ou dans un Ordre ou hors du royaume, ne devant ni ne pouvant combattre, alors celui-là peut être défié, même si ce mal, injure ou tort ne peuvent être prouvés par témoins, sauf pour un vol manifeste.

Les mêmes cérémonies connues en France se déroulent en Angleterre, à propos des duels et des gages de bataille, aussi il ne convient pas de les répéter ici.

Poursuivant mon propos, je dis que si on connaît d'autres formes de gages de bataille dans la majeure partie du monde, quoique ces formes ne soient pas décrites ni objets de lois et d'ordonnances, ce sont tout de même des coutumes autorisées par les rois et les princes de par le monde. Ainsi, si un chevalier ou gentilhomme dit à un autre: "Untel, vous avez dit que j’ai dit ou fait telle chose, et si vous le confirmez, je soutiendrai le contraire contre vous, et je vous donne des gages pour cela ", il doit alors lui donner un gant ou un chaperon ou autre chose semblable, et si l'autre persiste et prend le gage, aucun des deux ne peut en rester là et doit poursuivre jusqu'à la bataille, sans demander la permission du prince de la terre. Si l'un des deux arrête de poursuivre, il ne peut plus désormais prétendre être noble, il ne peut plus défier, ni avoir un office ni un honneur dus à un noble. Si un tel cas est mené à son terme, il se déroule ainsi, tous deux ensemble supplient le roi de leur donner un terrain en sécurité; le roi doit beaucoup se démener pour les réconcilier si possible, et sinon, il doit les mener dans un champ; et se déroulent alors les cérémonies selon la coutume du royaume où cela se produit, en leur donnant un endroit pour combattre. Quel que soit celui qui affirme qu'il a le droit de ce défi, et celui qui se rend à l'autre, celui-là doit recevoir la peine que selon les lois du royaume il doit recevoir en ce

12. VII ${ }^{e}$ Partida, Titre XXIII, Op. cit., p. 1431-1432. On est assez loin dans ces paragraphes du duel judiciaire ou des tournois ; Diego de Valera le juriste a eu du plaisir à inclure ces développements. 


\section{BULLETIN HISPANIQUE}

cas qui a provoqué le défi. Si l'affaire n'entraîne aucune peine selon la loi, celui qui est vaincu reste néanmoins infâme, ne pouvant avoir d'office ni d'honneur dus habituellement aux nobles. Si l'un des deux meurt dans le champ sans sêtre dédit, il est proclamé aussi honorable que celui qui l'a tué.

\section{Commence ici la seconde partie, dans laquelle est exposée la forme la plus éprouvée reconnue habituellement pour les combats de courtoisie}

Nous avons vu comment les saisies judiciaires, les duels et les gages de bataille doivent se dérouler, selon les lois de France, d'Espagne, d'Angleterre; il reste à voir comment les chevaliers et les gentilshommes doivent posséder des armes qui relèvent de leur privilège particulier et de leur noblesse. Le chevalier ou le gentilhomme qui veut porter de telles armes, doit suivre deux façons : il doit demander à un autre chevalier ou un autre gentilhomme de lui fournir certaines armes qui lui auront été délivrées par écrit, ou alors il porte une devise qui est réservée à un chevalier ou à un gentilhomme. Celui qui veut défendre ces armes, doit avoir d'abord la licence de son souverain seigneur; alors, s'il sort de la terre où a cours sa devise, il doit, avant de la montrer, avoir la licence du prince ou seigneur de la province où il veut exposer cette devise, et il doit la porter pliée sur le côté droit. S'il la porte découverte, dès qu'elle sera vue, il ne pourra plus du tout la porter, sauf si c'est sa devise personnelle, alors il peut vraiment la porter même si elle a été dépliée, et il l'enfile alors du côté gauche. S'il veut la garder repliée, il doit la recouvrir d'un voile et la garder ainsi jusqu'à l'appel, et alors seulement il doit la déplier, et puis la porter ainsi jusqu'à la fin de l'emprise d'armes. A ce propos on a longuement débattu devant moi à la cour du seigneur Philippe de Bourgogne, qui vit en ce moment, parce que j'avais gardé ma devise repliée et je ne l'ai découverte qu'après l'appel jusqu'à la fin des armes; le débat fut déterminé par le dit seigneur duc, sur le conseil de ses barons et chevaliers de sa cour de cette façon: je pouvais porter ma devise jusqu'à la fin des armes, et j'avais créé une distinction en la portant sans être totalement découverte, et découverte seulement à la fin.

Le chevalier ou le gentilhomme qui entreprend de telles armes, doit tenir dans sa main ses diplômes officiels scellés du sceau de ses armes, disposés à la même hauteur sans aucun avantage visible, au moment où l'emprise d'armes a été proclamée, puis il doit les donner de sa main propre ou de la main de son officier d'armes à celui qui relève son emprise. Il doit faire très attention que dans ces armes de courtoisie, on n'appelle pas un noble de haut lignage, dignité ou état supérieurs à lui-même, car ceux qui font cela sont très répréhensibles, quoique le droit admette qu'un pauvre chevalier ou gentilhomme appelle en bataille un 
grand seigneur, cela ne se produit que dans les armes forcées nées d'une querelle. Mais dans les armes de courtoisie, aucun grand seigneur ne doit répondre à une telle requête, même s'il est appelé en personne, sauf si par gentillesse ou pour faire honneur à celui qui l'a appelé il désire le traiter en égal.

Les protocoles à suivre dans ces armes sont ceux-ci : celui qui les entreprend doit entrer le premier dans les lices et en sortir le dernier, et il doit se tenir à la droite du prince, sauf si ce chevalier perd sa devise, car en ce cas celui qui la perd doit sortir le premier. Si les armes se font à pied, les deux adversaires doivent endosser leur cotte d'armes par-dessus leur harnais, mais sils sont à cheval, ce sont leurs officiers d'armes qui les portent devant eux. Peuvent de même, pendant de tels combats, entrer dans les lices tous les chevaliers et gentilshommes qui y participent, ce qui fut organisé par l'empereur Charlemagne, comme on le lit dans le second livre de l'Histoire Teutonique ci-dessus citée.

\section{Commencement de la troisième partie qui traite du principe ou fondement des armes et des enseignes et des différentes cottes d'armes et enseignes}

Ainsi, j'en ai terminé, Prince très illustre, avec la seconde partie. En suivant mon propos, je passe à la troisième où je vais traiter des principes et des fondements des armes et des enseignes, comme on le suit dans le Neuvième Livre de l'Histoire Teutonique et dans le livre intitulé de raptu Ganimedes, dans lequel Valère Maxime établit qu'il y eut un roi en Crète nommé Jupiter, qui entendant parler de l'extrême beauté et de la grâce juvénile de Ganymède, fils de Troyon roi de Troie, et voulant l'avoir à son service, alors que dans sa maison étaient élevés les fils des plus grands princes du monde, l'envoya chercher de façon répétée mais, sur le refus de Troyon, Jupiter indigné de sa réponse lui envoya son défi. Troyon releva ce défi et tous deux livrèrent bataille avec une foule innombrable de gens. Jupiter coupa une branche de laurier comme enseigne et la fixa sur un très haut mât, selon la coutume d'alors, mais un aigle volant au-dessus s'y installa tout à coup; tout le monde de l'ost le vit et proclama que c'était un signe de victoire, et Jupiter décida désormais de porter une enseigne avec une aigle, pour rappeler ce qu'on avait vu. Après la bataille, menée avec grand courage des deux côtés, Jupiter ayant remporté la victoire, il garda Ganymède dans son pouvoir, et les poètes qui aiment les métaphores chantèrent tous que Ganymède avait été enlevé dans les serres d'un aigle descendant du ciel sur l'ordre de Jupiter, qui désormais porta pour armes l'aigle noire sur champ d'or. On affirme que ce furent là les premières armes ou enseignes portées dans le monde et que c'est sur cet exemple que tous les princes et seigneurs prirent des armes à leur volonté. 


\section{BULLETIN HISPANIQUE}

D'autres disent que le premier inventeur des armes fut le grand Alexandre de Macédoine, dont on raconte qu'il dut livrer bataille au roi Darius et que de chaque côté, il y avait une infinité de gens amassés, et qu'en grand conseil, il décida de combattre par escadres, chaque escadre recevant une enseigne, observée par tous, et ainsi il eut la victoire sur Darius; le dit Alexandre donna à tous ses ducs, chefs et capitaines et principaux chevaliers de son ost, certaines armes qu'ils portèrent par la suite. Le premier récit semble cependant plus plausible, et à ce sujet Bartole, dans le traité de Insignis et armis dit que les armes ont été trouvées pour que les hommes fussent mieux reconnus. Voici, Prince très sérénissime, ce que, du principe des armes ou des signalements, j'ai pu comprendre.

Très longtemps après, Jules César, premier empereur au monde, si audacieux et vaillant chevalier comme le disent les histoires, désirant que les chevaliers et les gentilshommes fussent distingués, craints et honorés par les autres, leur donna de belles marques et prééminences, et des armes et des enseignes, pour les reconnaître. Il créa douze vieux chevaliers, qui l'avaient longuement servi dans ses guerres, pour rois d'armes et leur donna l'ordre d'être toujours présents dans les batailles en portant sur leur poitrine son blason, mais sans porter alors aucune arme offensive, afin d'observer les hauts faits des chevaliers et des gentilshommes et par la suite de les lui relater. Ainsi, chacun d'eux devait être rémunéré et gratifié selon ses mérites, et de cette obligation, depuis, on a décidé de définir tous les faits d'armes. L'empereur le fit publier de par le monde, et fit donner à ses rois d'armes sa sauvegarde devant tous ses ennemis, pour leur permettre d'être présents dans toutes les batailles afin d'attribuer l'honneur dî̀ à chacun, et puis se charger aussi de toutes les ambassades, et des défis, ou encore des messages de trêve ou de paix et encore de toutes sortes de choses, sans avoir à chaque fois une nouvelle sauvegarde ou un sauf conduit, et il leur donna les prééminences qui suivent.

La première est que les rois d'armes portent les armes du dit empereur sur la poitrine, qui sont d'aigle noire sur champ d'or, car ce furent les armes prises dans l'Empire pour rappeler que ce furent les premières connues, comme il a été dit. Deuxièmement, les rois d'armes occupent toujours un lieu qui a le privilège de sauvegarde, de par leur seule personne. Troisièmement, ils doivent être présents à tous les conseils de guerre et donner leur avis. Quatrièmement, toutes les lettres écrites en langue inconnue de l'empereur, sont transmises aux rois d'armes ou au plus discret d'entre eux, pour les interpréter et en faire un rapport. L'empereur voulut alors donner à ses rois d'armes des états très honorables, donnant à chacun quatre servants à cheval; et dès lors, tous les princes de ce monde imitèrent ces mesures. Parmi eux, bien longtemps après, Charlemagne, roi de France, empereur des Romains, le plus notable en vertu des princes de son temps, et le plus entendu en actes de noblesse, ajouta beaucoup d'éléments dans les armes et les enseignes et dans l'office des armes. Il ordonna ainsi trois différentes cottes d'armes et sept 


\section{LE TRAITÉ DES ARMES DE DIEGO DE VALERA, VERS I455-I460}

enseignes, dont nous allons donner ici les noms et les formes de chacune, pour une meilleure information. Il ordonna les dignités selon chaque personnalité, comme on va le voir. Il établit de même le noble office des armes de cette façon: tous les princes ne reconnaissant personne de supérieur dans le domaine temporel, devaient avoir des rois d'armes, des hérauts et des poursuivants, auxquels il attribua encore des prééminences en plus de celles qui avaient été définies par le premier empereur, car il leur permit d'aller librement de par le monde en portant le blason d'armes sur la poitrine, sans être arrêté ni payer de tribut ni de droit de passage, et il le fit admettre par tous les princes de son temps. Ils devaient être par tous les princes et généralement par toute la noblesse, distingués, honorés, aidés; ceci ne fut pas sans cause, car ils servent la noblesse et ils doivent être en retour soutenus par la noblesse.

Il fut encore ordonné par Charlemagne que tous les débats soulevés entre gens de guerre à propos de leurs affaires, fussent déterminés par les rois d'armes, en accord avec les maréchaux. Et puis encore que, dès qu'ils sortiraient de leurs terres pour faire la guerre aux ennemis, ils donnent aux officiers d'armes un jour de solde de tous les chevaliers et gentilshommes, en répartissant cette solde de la façon suivante: chaque roi d'armes valait deux hérauts, chaque héraut, deux poursuivants, et sitôt que les rois et les princes prenaient par force d'armes une ville ou une cité, l'officier d'armes devait recevoir une maison avec tout ce qui s'y trouvait, celle qu'il voulait choisir, à part la forteresse s'il y en avait une ou la maison forte de la localité. Il fut encore ordonné par Charlemagne que lorsque les armes se jouaient en présence d'un prince, armes à outrance ou armes de courtoisie, tous les officiers d'armes devaient être présents dans les lices.

Les charges données par cet empereur sont les suivantes. D’abord, dès que se décide une bataille ou un combat, les officiers d'armes doivent avertir tous les chevaliers et les gentilshommes de tenir prêtes leurs cottes d'armes pour le jour fixé, sous peine de déshonneur. Ce jour-là, les officiers d'armes doivent porter les cottes d'armes royales et, une fois vêtus, aller devant la bannière royale. Lorsque commence la bataille, ils doivent se poster dans les lieux où ils jugeront le mieux et les plus loyalement les phases de la bataille, sans porter eux-mêmes aucune arme offensive, pour que les princes aient la certitude que tout se déroule selon le droit. Puis, toutes les proclamations que les princes ordonnent de lancer dans la guerre, doivent être faites par les officiers d'armes, de même que toutes les réclamations qu'en temps de guerre, les princes s'envoient les uns aux autres, ou aux cités, villes, communautés, et ces officiers ont en effet la sauvegarde de tous les gens, depuis le temps de l'empereur Charlemagne. Si quelqu'un, dans les divers actes de guerre, ou en bataille comme on l'a dit, ou de toute autre façon, tue, blesse, ou porte un déshonneur, un mal, un tort, à un officier d'armes, il tombe alors dans le cas de délit et peut à ce sujet être provoqué, comme on le voit dans 


\section{BULLETIN HISPANIQUE}

le second livre de l'Histoire Teutonique susdite, sauf si cet officier d'armes est l'agresseur ou le fauteur de quelque scandale ou se trouve pris en combattant ou portant dans la bataille des armes offensives. Et puis encore, les officiers d'armes doivent faire les proclamations lorsque le roi déclare quelqu'un traître; lorsque cela arrive, l'officier d'armes doit recevoir 100 francs sur les biens du condamné. Si on déclare tombée en traîtrise une communauté, une cité, une ville, il doit recevoir 1000 francs de tous ces biens collectifs. Et puis encore, tout officier d'armes doit faire toute requête, ou toute ambassade, à la demande de tout chevalier ou gentilhomme, aux frais de celui qui le demande, sauf si ce chevalier ou gentilhomme se trouve alors en prison ou en grande nécessité; car en ce cas, l'officier d'armes doit pourvoir à ses propres dépenses et, de plus, il doit aider le plus possible celui qui l'a mandé.

Poursuivons maintenant notre propos, Prince très puissant; je précise qu'existent trois sortes de cottes d'armes, la cotte (cota de armas), la jaque de mailles (tinicla) et le haubergeon (plaquín); certes, ces noms indiquent qu'il y a divers modèles, mais ils désignent tous trois une seule et même chose, car sur chaque cotte se mettent les armes, mais la différence vient de la façon ou la coupe, selon les modèles.

Il faut souligner que la cotte d'armes convient au roi ou aux vieux chevaliers, qui doivent combattre plutôt par le conseil que par leurs bras; et de même la portent les officiers d'armes. La jaque de mailles est plutôt portée par les plus grands seigneurs de l'ost, en âge de combattre. Le haubergeon est porté par tous les chevaliers et les gentilshommes qui doivent combattre. Cette habitude est observée depuis peu de temps en France et en Angleterre, où aucun chevalier ou gentilhomme ne peut entrer en bataille sans porter cotte d'armes ou jaque ou haubergeon. Autrefois, en France on suivait la coutume que, certains jours avant la bataille, si on devait l'organiser, les rois d'armes et les hérauts avec leurs trompettes, prévenaient les chevaliers et les gentilshommes qu'ils devaient s'apprêter avec cottes, jaques, haubergeons, pour le jour de la bataille, sous peine de déshonneur. Si le combat devait être entrepris par surprise, les officiers le disaient de tente en tente à chaque capitaine. Si l'un d'eux était trouvé dans l'affrontement sans cette cotte ni jaque ni haubergeon, il était gravement puni, car il s'était déshonoré en allant sans se faire reconnaître et sans porter ses armes comme il le devait.

Ily a sept sortes d'enseigne, la bannière, le pennon, le panonceau, la banderole, le guidon, l'étendard, et le gonfalon. La bannière est portée par les rois, les ducs, les marquis, les comtes, les vicomtes, les amiraux et les barons. Les pennons reviennent aux Ordres, ceux de Santiago, Calatrava, Alcantara, et Saint-Jean. Le panonceau est l'emblème des cités, villes et communautés. La banderole doit être placée sur la sépulture de tout chevalier ou gentilhomme qui peut aussi la 


\section{LE TRAITÉ DES ARMES DE DIEGO DE VALERA, VERS I455-I460}

garder dans la lice, sur la démarcation, lorsqu'il doit combattre ou faire des armes. Le guidon est porté par les empereurs et les rois, du moins auprès de leur personne, lorsqu'ils sont dans l'ost, pour qu'on sache où ils se trouvent, et en leur absence, par les connétables et les capitaines généraux des osts. L'étendard est l'enseigne de tout chevalier ou gentilhomme ou capitaine qui a la charge de mener des gens d'armes. Le gonfalon n'a pas de différence avec l'étendard, mais est plus petit et porté par les capitaines des petits effectifs. Pour bien retenir tout cela, on a dessiné ici les modèles de toutes ces enseignes, en sachant bien que sur l'étendard, le guidon et le gonfalon on ne doit jamais tracer les armes, mais seulement la devise, ou alors diverses couleurs.

Il convient encore de préciser qu'on distingue la bannière royale et la bannière des autres dignités. La bannière royale doit être plus longue que large, alors que les autres bannières sont carrées. Il faut de même distinguer la bannière de chacune des dignités, et la bannière des descendants des premiers titulaires; en effet, il faut d'abord savoir que chaque dignité doit porter des armes attitrées, et seul peut les porter le titulaire de cette dignité, puis après lui, son fils premier né, avec la différence que je donnerai plus loin; les autres fils doivent porter la bannière avec pans, de la façon décrite. Les rois et les princes, en temps de guerre, doivent porter bannière, ou étendard, ou guidon. La bannière ne doit jamais être déployée, sauf en vue des ennemis, au moment convenu pour la bataille ou le combat. De même, doivent porter l'étendard tous ceux qui ont leur bannière dans la bataille, sans la déployer avant le moment de combattre.

Voyons maintenant quelles sortes d'armes on connaît et comment on peut les perdre. J'affirme qu'on peut obtenir des armes de quatre façons: par héritage des prédécesseurs, par don des princes, par gain dans une bataille, ou par invention personnelle. Quelle que soit la façon, les armes une fois obtenues passent aux descendants légitimes selon le droit commun. Les armes obtenues par héritage, sobservent partout, car généralement tous les descendants portent les armes que portaient leurs ancêtres. Que les princes aient l'habitude de donner des armes à ceux qu'ils anoblissent, c'est la coutume très générale dans le monde. Les armes obtenues dans une bataille doivent être expliquées, car à ce propos il faut distinguer les armes de dignité et les armes de lignage. Si elles sont de dignité, elles ne peuvent être obtenues d'une autre façon, sauf si on obtient cette dignité à laquelle les armes sont attachées, comme le dit bien Bartole dans son traité de Insignis et armis, et on voit cela tous les jours. Ainsi l'empereur Sigismond, selon son lignage, aurait dîu porter les armes de Luxembourg. Mais, ayant obtenu l'empire et les royaumes de Hongrie et de Bohême, il porta les armes de ces dignités. De même le roi Alphonse d'Aragon, par son lignage devrait porter les armes de Castille et de León, mais ayant les royaumes d'Aragon et de Sicile, il en porte les armes; de même le font tous les autres rois et princes qui ont de nouveaux 


\section{BULLETIN HISPANIQUE}

royaumes et seigneuries. Il faut encore souligner que les armes de dignité se convertissent en armes de lignage pour les descendants, sauf pour l'héritier de la dignité, qui ne peut les perdre qu'en perdant son droit à hériter de cette dignité. A propos de ces armes ainsi portées par lui, on doute si celui qui les prend, peut les porter. Bartole dans son traité susdit, assure que oui, et il en donne la preuve en citant plusieurs lois, dont cette raison que les armes furent inventées pour que les hommes fussent reconnus, tout comme les noms et les prénoms, et puisqu'il est licite à chacun de prendre le nom qu'il veut, il lui est tout autant possible de prendre des armes ou des signes à volonté, tant que ces armes n'appartiennent pas déjà à quelqu'un d'autre, car en ce cas cela peut lui être défendu par celui qui les a portées en premier. Sauf, si l'un d'eux vit dans un royaume et le second dans un autre Etat, car en ce cas il n'y aurait aucune raison de se quereller, ni l'un ni l'autre ne pouvant affirmer que sa maison ou sa propriété ont la prééminence sur l'autre pour en porter les armes. Il faut relever à ce propos que si chacun peut porter le nom d'un autre, il ne peut pour autant en porter les armes. Il ne sagit pas du tout de la même affaire, car il est certain que chacun peut porter le nom principal d'un autre, comme Pedro ou Juan, mais non pas son patronyme, sauf sil est de son lignage. Il en est de même des armes, qui ne relèvent que d'un lignage. Sinon, le premier essuierait un préjudice, si un homme de moindre état ou lignage prenait ses armes et son patronyme, et le temps passant, on ne saurait plus lesquels furent de la maison, les nobles ou au contraire les usurpateurs. Il faudrait obliger l'un ou l'autre à les abandonner, et le juge, de par son office, devrait l'ordonner pour éviter le scandale qui ne manquerait pas de survenir. Mais des armes prises par quiconque en veut, si elles ne sont pas à un autre, on le voit en effet de façon très répandue, en Allemagne, en Bohême, en France, en Angleterre, en Italie, où tous les citadins prennent les armes à leur guise, les font peindre sur leurs maisons et dans les églises dont ils sont les paroissiens. C'est sur ce point peut-être qu'on peut établir une différence entre les chevaliers et les gentilshommes d'une part, et les plébéiens d'une autre. Les chevaliers et les gentilshommes mettent leurs armes sur les hôtels publics, sur les cottes d'armes, et sur bien d'autres choses comme cela leur plaît, mais les plébéiens ne le font que dans leurs maisons et dans leurs paroisses. Lorsqu'il se produit qu'un plébéien est anobli par le prince, il choisit des armes qu'on trouve sur des cottes d'armes et partout où en portent les nobles d'anciens lignages, à moins d'en recevoir de nouvelles du prince, pour avoir une plus haute autorité. Et même en Castille on voit que la plupart des plébéiens prennent toutes les armes qu'ils veulent avoir! Il faut savoir que les armes données par le prince, sont de plus haute autorité, comme le dit Bartole dans le traité susdit, si bien que si entre deux hommes égaux en dignité, il y a quelque litige pour savoir quelles armes doivent avoir la prééminence, on doit préférer celles qui ont été données par le prince. De même 


\section{LE TRAITÉ DES ARMES DE DIEGO DE VALERA, VERS I455-I460}

celui qui a reçu ses armes du prince, ne peut jamais être empêché de les porter, même si quelqu'un d'autre les avait anciennement portées.

Si les armes sont de lignage, elles peuvent être perdues en quatre occasions: si quelqu'un dans une bataille a perdu sa bannière, alors qu'il n'est ni tué ni prisonnier et qu'il n'est pas resté sur le champ à la merci des ennemis; celui qui a pris sa bannière pourra désormais porter ses armes, car on ne doit jamais se séparer de sa bannière et de sa cotte d'armes, sauf par la mort ou la prison ou lorsque le seigneur de ces armes reste sur le champ à la merci des ennemis. Deuxiemement, perd ses armes tout chevalier ou gentilhomme fuyant la bataille, alors que son roi ou son prince ou son capitaine général ne fuit pas, quoique, à ce propos, il y ait bien des différentes coutumes dans ce monde. Selon le droit de l'Empire, ceux qui font cela, doivent être exécutés comme traîtres et leurs biens sont saisis par l'empereur, et leurs fils restent ennemis de la chose publique et exilés hors de la terre. En France, ceux qui fuient sont déclarés infâmes, perdent leurs armes et tous leurs honneurs et dignités de noblesse et gentillesse. En Castille, ils devraient être exécutés pour traîtres, et leurs biens saisis par le roi. Troisièmement, perd ses armes quiconque pour délits et mauvaises coutumes a perdu sa noblesse ou gentillesse. Quatrièmement, si deux chevaliers ou deux gentilshommes sont affrontés en bataille ou dans une querelle, et si l'un demande à l'autre de lui épargner la vie alors qu'il a été défié, celui-là peut perdre ses armes et celui qui l'a mis dans cette extrémité peut désormais les porter.

On pourrait soulever deux points : d'abord, si un comte ou baron a vendu son comté ou sa baronnie, peut-il porter encore ses armes qu'il portait de par cette seigneurie? Deuxièmement, les fils bâtards peuvent-ils porter les armes de leur père? A la première question, je réponds qu'on doit rechercher si ce comte ou baron a eu le comté ou la baronnie par héritage ancestral ou si le prince le lui a donné, ou sill l'a acheté. S'il l'a eu de ses géniteurs, même s'il vend la dignité, il peut toujours en porter les armes et la bannière, non plus comme un comte ou baron, mais avec un pan supplémentaire, comme un homme descendant de lignage de bannière, et celui qui l'achète doit porter la bannière carrée, sans aucune différence. Si le roi lui a donné la dignité ou sill l'a achetée, en vendant il perd tout le droit relatif aux armes et à la bannière, et dès lors c'est celui qui a acheté le comté ou la baronnie qui doit en porter les armes et la bannière. Et j'ajoute encore qu'il faut distinguer si les fils sont légitimes ou bâtards; s'ils sont légitimes, j'affirme que selon le droit commun, ils peuvent porter les armes de leurs pères sans aucune différence; mais s'ils sont bâtards, ils ne le peuvent, selon Bartole dans le livre susdit, quoique les coutumes divergent dans le monde, surtout en France et en Angleterre où tous ceux qui ne sont pas nés de légitime mariage portent les armes de leur père avec une marque distinctive, ou bien toutes les armes dans un seul quartier de l'écu, ou trois des quartiers aux couleurs 


\section{BULLETIN HISPANIQUE}

qu'ils veulent, ou alors sur l'écu entier une bande renversée ou barre qui brise les armes. Ainsi, non seulement entre les légitimes et les bâtards on fait la distinction, mais encore on la fait entre l'aîné et le cadet, et entre tous les frères. Car l'héritier de la maison porte, pour différence de son père, un lambel sur les armes, comme l'avait fait François, premier né de Bretagne, du vivant du duc Jean son père; ou alors l'héritier porte les armes d'une autre dignité jointes à celles du père, tel le Dauphin, portant les armes de France et de Dauphiné en quartiers, pour se démarquer du roi ; tel le comte de Charolais (il porte les armes de son père, le duc de Bourgogne, et celles du Charolais) pour sa différence, et tous les autres frères font encore des distinctions entre eux : une bordure ou une orle, ou sur l'écu une rose ou une croisette, ou une roue d'éperon, ou un oiseau, ou des choses semblables. Il faut encore savoir que les fils légitimes sont ceux qui naissent d'un homme et d'une fermme libres de tout autre lien, elle-même se trouvant dans la maison non pas pour la luxure, mais au contraire pour la descendance à procréer. Les bâtards sont ceux qui naissent d'union non légitime, comme on le lit plus spécialement à la fin de mon traité Espejo de Verdadera Nobleza que jai écrit. Mais comme cela ne fait pas exactement partie de mon sujet, je veux passer maintenant au blason des armes.

Pour que cela soit aisé à comprendre, il faut se mettre d'accord sur le vocabulaire. Prince très catholique, je rappelle que le vocabulaire est ici français, alors qu'en notre langue le blason veut plutôt dire déclaration ou démonstration, et ceux qui disent "blasonner des armes" en prenant des termes de pierreries, de vertus, d'éléments, de métaux, se trompent, car en ce cas il faudrait dire " comparer ou approprier", alors que "blasonner" veut seulement signifier démontrer ou déclarer les armes. Ceci précisé, il faut savoir qu'existent sept couleurs pour peindre les armes, le jaune qui en blason est appelé or par les Français, le blanc qui est argent, le rouge qui est gueules, le pourpre ou violet, le vert qui est dit sinople, l'azur qui est le bleu ou l'azur, et le noir qui se dit sable. Mais les officiers d'armes disent plutôt deux métaux et cinq émaux; malgré leur correction, il me semble qu'on peut parler de sept couleurs, puisque chaque métal a sa couleur, dont on peut peindre les armes aussi bien que d'un métal. De même beaucoup d'officiers d'armes disent que les armes qui sont de deux métaux, d'or et d'argent, ou de deux couleurs, comme de vert ou de pourpre, sont fausses. Ceci, sache Votre Grandeur, ne doit pas être : s'il en était ainsi, les armes de Jérusalem seraient fausses, car elles sont de champ d'argent à la croix d'or, et ces armes ont été créées par Godefroy de Bouillon, quand il conquit Jérusalem, en estimant qu'elles étaient plus nobles que les autres. S'il en était ainsi, de même, seraient fausses les armes de Mendoza, qui est l'une des plus nobles et des plus anciennes 
baronnies d'Espagne ${ }^{13 .}$ On ne peut pas croire qu'un royaume si ancien et une baronnie si noble porteraient des armes fausses. Certains officiers d'armes disent encore que les armes qui ne sont pas de figures naturelles (cosas vivas) n'en sont pas, mais sont des signes; sauve Votre Révérence, ils se trompent encore, car aucune autorité ne peut prouver cela. Si c'était la vérité, ni le roi de France, ni vous seigneur, ni le roi de Navarre, ni les ducs d'Autriche, ni les ducs de Bavière, ni beaucoup d'autres princes et seigneurs ne pourraient affirmer tenir des armes! Et affirmer cela est bien une erreur reconnue par tous ${ }^{14}$. Mais la vérité est que ce que nous appelons des armes, représentant des éléments vivants ou tout autre chose, à proprement parler sont des signes par lesquels se définissent les dignités ou les lignages ou les personnalités.

Il faut encore savoir qu'en héraldique on trouve deux signes, qui ne se disent ni ne se doivent dire métaux ou émaux, qui sont les hermines et les vairs, et nous disons seulement de celui qui les porte : "portant d'hermine ou de vair ". Il faut préciser que l'hermine doit être blanche et noire, la partie principale blanche, et le vair est blanc et bleu; et sil arrive que quelqu'un porte des vairs ou des hermines d'autres couleurs, on ne doit plus dire d'hermine ou de vair, mais on doit dire "portant vairé ou herminé", ou en notre langue trae armiñado e verado.

Il faut distinguer les émaux les plus nobles, donc savoir que plus noble est la couleur quand on peut la comparer aux plus nobles choses. Car chacune des couleurs peut être comparée et identifiée à bien des choses, aux éléments, aux corps célestes, aux choses élémentaires, aux vertus. Aux éléments, par exemple, le jaune sera comparé au feu, qui en est le plus noble; aux corps célestes, au soleil; aux choses élémentaires, à l'or, à l'étoupe, au chèvrefeuille; aux vertus, à la tempérance. Le blanc, aux éléments nous le comparerons à l'air clair et diaphane; aux corps célestes, à la lune; aux choses élémentaires, à l'argent, à la perle, au lys; aux vertus, à la chasteté. Le rouge, aux éléments, au feu lui aussi ; aux choses élémentaires, aux éclairs, au rubis, au fer, à la rose; aux vertus, à la magnanimité ou grandeur de cour. Le moiré ou violet, ne peut se comparer aux vertus, il n'en a aucune conformité; mais aux choses élémentaires, au rubis balai, au cuivre, à l'oillet, à la pourpre, car il en a toutes les couleurs. Le vert ne peut se comparer à aucun élément; aux choses élémentaires, aux prés, aux arbres, à

13. Le blason de Jérusalem est en effet à enquerre, d'argent à la croix d'or recroisetée de même. Les Mendoza portent de sinople à la bande de gueules filetée d'or, ce qui est également à enquerre.

14. L'écu de France porte les lys, celui de Castille le château, celui de Navarre le rai d'escarboucle, celui d'Autriche de gueules à la fasce d'argent, celui du Portugal des besants à l'orle de châteaux, et celui de Bavière est écartelé en 1 et 4 de sable au lion d'or et en 2 et 3 d'argent au chef fléché de gueules. 


\section{BULLETIN HISPANIQUE}

l'émeraude; aux vertus, à l'espérance. Le bleu, aux éléments, à l'eau; aux choses élémentaires, au ciel, au saphir, à l'iris, au fer; aux vertus, à la loyauté. Le noir, en éléments est comparé à la terre; en choses élémentaires, aux ténèbres, au jais, au plomb; en vertus, à la fermeté et à l'honnêteté; quoique beaucoup d'officiers d'armes le comparent au diamant, avec Votre Révérence, ceci est faux, car le diamant est lumineux et clair de nature, et même si certains diamants sont plus clairs que d'autres, que les uns sont cristallins et les autres plombés, et d'autres encore de couleur olivâtre, il n'empêche que tous les diamants sont si clairs qu'on peut voir toujours leur intérieur; et s'ils ont quelque obscurité, c'est qu'on y a introduit une teinture, et comme l'artificiel ne peut l'emporter sur le naturel, aucun ne peut être privé de sa clarté, et il est déraisonnable de préférer l'artificiel au naturel. Ceci dit, chacun pourra facilement reconnaître les couleurs nobles et donc savoir où les placer. Mais pour plus de précision encore, très excellent Prince, il faut savoir que certaines armes ne portent que des émaux, et d'autres ont des bêtes, des poissons, des oiseaux, des fleurs ou des corps célestes.

Dans les armes de divers émaux, il faut savoir que l'écu peut se partager de trois façons fondamentales, soit en bande, en fasce, en pal. Mais il y a d'autres choix, pour partager les armes, en quartiers, qu'en langue française on dit en cartels; en girons, dits partout girons; ceint ou de flanc; échiqueté qui se dit ainsi, et losangé. Dans l'écu, on peut encore distinguer le chef et la pointe; il faut prendre pour règle que la principale partie de l'écu se dit le champ, et la plus restreinte la pointe ou le chef; la pointe peut entrer en giron et couvrir la moitié de l'écu, et on ne peut plus alors l'appeler pointe, mais mantelet. L'écu peut aussi avoir plusieurs bandes ou fasces ou pals; lorsque la pointe et le chef sont d'un même émail, on parle du champ; pour le contraire, on doit dire bandé de telles pièces; de même pour les fasces et les pals. Les armes qui portent des bêtes, oiseaux ou poissons, des fleurs ou des corps célestes, il faut les peindre selon l'attitude qui montre leur plus grande qualité et leur plus grande beauté : si nous voulons peindre un lion, qui est un animal fier, nous devons le placer sautant, et un léopard, passant; c'est pourquoi les officiers d'armes disent couramment que le lion est rampant et le léopard passant; les lions qui sont tracés ainsi et dont on dit qu'ils sont rampants ou passants, sont fixés ainsi parce que c'est leur façon la plus naturelle, et on dit seulement: "porte un lion d'or sur champ de sinople" ou "porte un léopard sur champ d'azur". S'il arrive qu'on voit un lion dont le torse est tordu, ou dressé sur ses pattes, ou tenant quelque chose dans ses pattes, il faut le détailler; c'est ainsi qu'il faut blasonner les armes du duc de Brunswick, qui sont de deux lions adossés l'un contre l'autre, de pourpre sur champ d'or, et nous disons : "portant deux lions adorsés de pourpre " 15.

15. Plus exactement, pour les ducs de Brunswick, de gueules aux deux léopards d'or adorsés, armés et lampassés d'azur. 


\section{LE TRAITÉ DES ARMES DE DIEGO DE VALERA, VERS I455-I460}

Il faut encore savoir quil y a neuf signes qui habillent le cinquième de l'écu, quoique maître Alain Chartier dans un bref traité quil composa sur le blason, affirme quils doivent couvrir le tiers ${ }^{16}$. Les officiers d'armes acceptent généralement cela, mais la coutume ne le suit pas, et nous croyons que toutes les figures prennent le cinquième de l'écu, le chef ou tête de l'écu, le chevron, la bande, la fasce, le giron, l'orle, la croix, le sautoir. Pour mieux comprendre cela, tous les écus avec figures seront dessinés à la fin de ce traité.

Il faut encore savoir que, quoique certains officiers d'armes disent que les bandes, fasces, chevrons, sautoirs, croix, doivent se compter lorsquion détaille l'écu, et les oiseaux, poissons, bêtes, fleurs ou corps célestes doivent se compter jusqu'au nombre de 16, j’affirme, sauve Votre Révérence, que tous ces éléments qui se lisent dans l'héraldique doivent se compter jusqu'à 10 et pas plus, car le nombre de 10 est parfait, car Notre Seigneur donna sa loi à Moïse en 10 commandements, et le prophète David disait à Notre Seigneur : "Je chanterai devant toi sur le psalterion à 10 cordes". Et au-delà de 10, on doit dire "semé de fleurs de lys ", ou de croix, ou d'étoiles, et des autres figures.

J'ai parlé dans cette ouvre si simple et si brève à un Prince si discret, que j'arrête ici d'expliquer toutes les subtilités du blason, qui sont habituellement connues des officiers d'armes. Si vous trouvez dans mon propos quelques erreurs, comme je n'en doute point, Votre grande prudence les relèvera, et je supplie Votre Royale Majesté d'ordonner leur correction et leur amendement, en attribuant la faute à mon faible savoir et non à ma volonté d'errer.

16. Alain Chartier (1385-1435) a écrit le Quadriloge Invectif, La Belle Dame sans Mercy, le Livre de l'Espérance, le Débat Patriotique, le Lay de Paix, le Bréviaire des Nobles, entre 1422 et 1429 , mais pas de traité d'héraldique. 


\section{RAPPEL BIBLIOGRAPHIQUE}

Coulet, Noël, Alice Planche, Françoise Robin, Le roi René, le prince, le mécène, l'écrivain, le mythe, Aix-en-Provence, 1982.

Flori, Jean, Chevaliers et chevalerie au Moyen Âge, Paris, 1998.

GILlI, Patrick, "Guerre, paix, alliance, duel ; la discipline de la violence dans les traités juridiques sur la guerre en Italie au XVe siècle », in Guerre, Pouvoir et Noblesse au Moyen Âge, Mélanges en l'honneur de Philippe Contamine, Presses de l'Université de Paris-Sorbonne, 2000, p. 323-341.

Jones, Michaël, "Vers une prosopographie des hérauts bretons médiévaux; une enquête à poursuivre", Comptes-rendus de l'Académie des Inscriptions et Belles Lettres, Paris, 2001, p. 1399-1426.

Le Règlement des conflits au Moyen Âge, XXXI ${ }^{\mathrm{e}}$ congrès de la Société des Historiens Médiévistes de l'Enseignement Supérieur Public, Angers, 2000, Publications de la Sorbonne, 2001.

Pastoureau, Michel, Les Armoiries, Typologie des sources du Moyen Âge occidental, Turnhout, 1976.

- Traité d'Héraldique, Paris, 1993.

- Bleu, Histoire d'une couleur, Paris, 2000.

Riquer, Martín de, Heráldica castellana en tiempos de los Reyes Católicos, Barcelone, 1986.

VALE, Malcolm, War and Chivalry, Athens, Georgia, 1981. 